ISSN 1536-9323

\title{
A Design Theory for Visual Inquiry Tools
}

\author{
Hazbi Avdiji ${ }^{1}$, Dina Elikan ${ }^{2}$, Stephanie Missonier ${ }^{3}$, Yves Pigneur ${ }^{4}$ \\ ${ }^{1}$ University of St. Gallen, Switzerland, hazbi.avdiji@gmail.com \\ ${ }^{2}$ University of Lausanne, Switzerland, dina.elikan@ gmail.com \\ ${ }^{3}$ University of Lausanne, Switzerland, stephanie.missonier@unil.ch \\ ${ }^{4}$ University of Lausanne, Switzerland, yves.pigneur@unil.ch
}

Abstract

\begin{abstract}
The Business Model Canvas project cleared the path for the development of a new tool type that we refer to as visual inquiry tools. Such tools build on design thinking techniques to allow management practitioners to jointly inquire into specific strategic management problems. As the interest in and the emergence of visual inquiry tools gain momentum, it is important to formalize the design knowledge that future designers can build on to develop such tools. Thus, we propose a design theory for visual inquiry tools based on the design knowledge accumulated within and across three projects: the Business Model Canvas, the Value Proposition Canvas, and the Team Alignment Map. We outline the design principles (among others) that should be followed for developing visual inquiry tools for other strategic management problems. Our study addresses the lack of guidance in the development of visual inquiry tools and the lack of methodological guidance in design science research on how to theorize and formalize knowledge across multiple projects. We provide a methodological process for analyzing multiple-project data by bridging methodological insights from design science research and qualitative methods from the social sciences.
\end{abstract}

Keywords: Strategic Management Problem, Visual Inquiry Tool, Joint Inquiry, Design Theory, Design Science Research, Design Knowledge Accumulation, Design Knowledge Theorization, Multiple-Project Analysis

Alexander Maedche was the accepting senior editor. This research article was submitted on November 30, 2017, and underwent three revisions.

\section{Introduction}

The reality that managers face today is increasingly characterized by strategic management problems that are wicked, unique, intangible, and hard to define and ultimately solve. This is, for instance, the case in information systems (IS) development (Dorst, 2011; John \& Kundisch, 2015), new product development and service design (Dunne \& Martin, 2006; Steen, Manschot \& De Koning, 2011), and organizational design (Camillus, 2008; Clegg, Carte, Kornberger \& Schweitzer, 2011). Since these problems are not governed by stable and linear causal mechanisms (Dunne and Martin, 2006; Farjoun, 2010), scholars and practitioners have begun to address them with iterative approaches such as design thinking and joint inquiry (Détienne, 2005; Martin, 2009; Steen, 2013). Joint inquiry is a process through which a group of diverse individuals who face an uncertain situation jointly define and explore a problem, and jointly generate and evaluate different hypotheses about how to solve it. These approaches are becoming more popular for strategic problems than traditional linear approaches since they allow for iterative and creative processes (Boland et al. 2008). 
Practitioners make use of various tools to navigate the complexity of joint inquiry (Dalsgaard, 2017; Nicolini, Mengis \& Swan, 2012). Among these various tools, we have, in recent years, seen an emergence of what we call visual inquiry tools. These tools support the process of exploration and ideation of a strategic management problem. Such tools include the Business Model Canvas (Osterwalder \& Pigneur, 2010), the Project Canvas (Habermann \& Schmidt, 2014), the Innovation Matrix (Van der Pijl, Solomon \& Lokitz, 2016), and the Customer Journey Map (Kalbach, 2016). These tools provide a shared and framed design space in which practitioners can jointly inquire into a strategic management problem. Recently, these tools have attracted considerable interest, as shown by the number of tools available and the extensive adoption of tools such as the Business Model Canvas, which has been downloaded more than 6 million times to date (Strategyzer, 2015).

Given their importance, a major shortcoming is that it is not clear how rigorously and theoretically sound these tools are designed. There is a lack of systematic or rigorous prescriptive knowledge to inform future developers designing such tools. Since this visual approach to joint inquiry may prove useful to address strategic management problems, developing prescriptions for their design is increasingly called for. The lack of such knowledge leaves room for potential inconsistent developments that are solely based on the imitation or replication of existing tools without a clear and rigorous conceptualization of the functions and forms of the intended design. Thus, we seek to answer the following question: How can we develop visual inquiry tools for specific strategic management problems?

To answer this question, we developed a design theory based on three independent design science research (DSR) projects that resulted in the design of three visual inquiry tools: the Business Model Canvas, the Value Proposition Canvas, and the Team Alignment Map. The theory integrates principles and knowledge from these three visual inquiry tools, each of which addresses a different type of strategic management problem. We based the development of our design theory on three extensive and longitudinal datasets spanning 7-17 years. Our design theory indicates that such tools have three fundamental pillars: (1) a conceptual model that frames and defines the strategic management problem at hand, (2) shared and visual design spaces in which practitioners can explore and try different solutions, and (3) a set of directions for use that users can follow to solve the strategic management problem.

In answering the research question, we also make a methodological contribution. We outline how design knowledge accumulation and theorization within and across projects can be conducted in DSR. There are currently no clear frameworks on how to theorize design knowledge derived from multiple projects, since most methodological developments in DSR either focus on how to conduct a research project (e.g., Hevner, March, Park \& Ram, 2007; Peffers et al., 2007) or on how to present and theorize design knowledge from single projects (e.g., Gregor \& Jones, 2007; Gregory \& Muntermann, 2014). Our methodological approach can inform other design science researchers who wish to develop design theories for multiple artifacts and projects.

\section{Literature Review}

Given that it is important for organizations to manage strategy's wickedness and thus to be able to formulate, align, and implement their strategies to remain competitive, it might be assumed that many different tools and techniques would have already been introduced to support this process (Aldea et al., 2018). Tools can take the form of any kind of object, concept, framework, method, or model that helps practitioners analyze and solve problems, make decisions, and collaborate with others (Lee \& Amjadi, 2014; Nicolini et al., 2012).

The 1980s saw the development of an extensive number of strategic management tools that are still widely used today, such as the Five Forces (Porter, 1979), strategic group maps (McGee \& Thomas, 1986) or the BCG growth-share matrix (Henderson, 1979). Such tools were among the first to target specific management activities and help practitioners analyze a situation and evaluate strategic choices (Jarzabkowski $\&$ Kaplan, 2015). These tools were developed based on the assumption that management activities mainly require procedural rationality (Simon, 1978) or the use of rational and causal thought processes to make decisions or devise solutions. Thus, these tools were primarily developed to aid rational analysis and decision-making processes (Cabantous \& Gond, 2011; Jarratt \& Stiles, 2010). Such decision-making processes are based on gathering data, narrowing down possibilities, and choosing the best one. This business approach values refining and polishing ideas without testing them prior to implementation. However, as uncertainty and complexity increase a strategy's wickedness, practitioners increasingly face issues they can no longer resolve by breaking problems down into smaller ones (Camillus, 2008; Teece, Peteraf \& Leih, 2016).

Moving beyond traditional strategic management approaches, joint inquiry through design thinking techniques (an approach that comes from the architectural world) has emerged as a valuable approach in strategy making (Boland \& Collopy, 2006; Steen, 2013). It is a recursive process through which multiple individuals (1) jointly define and explore a problem, and (2) jointly develop and evaluate 
alternative solutions to it. This process is less linear than traditional rational techniques in strategic management (Buchanan, 1992) and this approach to problem-solving has been shown to enhance innovation and, by extension, organizations' value (Gruber et al., 2015), especially in environments with great uncertainty (Lietdka, 2018).

Joint inquiry encourages the creation of alternatives and transforms the way that management problems are handled. Instead of refining their first ideas, architects and designers generate prototypes. These visual prototypes allow for easier representations of different possible scenarios, testing these different scenarios, and (re)presenting the selected solutions to all the stakeholders (Cooper, Junginger \& Lockwood, 2009). Thus, joint inquiry is particularly tailored to strategizing since it allows individuals and teams to adjust to unexpected changes (Razzuk \& Shute, 2012), handle uncertainty, and increase team engagement via the implementation of team processes. For instance, Ben Mahmoud Juini, Midler \& Silberzahn (2016) found that the limitations of project management in innovative solutions could be leveraged by joint inquiry.

Consequently, visual inquiry tools - tools that rely on joint inquiry techniques - have emerged over the past few years. Examples include the Project Canvas (Habermann \& Schmidt, 2014), the Innovation Matrix (van der Pijl et al., 2016), the Operating Model Canvas (Campbell, Gutierrez \& Lancelott, 2017), the Customer Journey Map (Kalbach, 2016), and the Market Opportunity Navigator (Gruber \& Tal, 2017). These tools build on design thinking techniques to guide practitioners in jointly inquiring into specific strategic management problems. For instance, the Business Model Canvas (Osterwalder \& Pigneur, 2010), the first and best-known example, has transformed business modeling by providing a design space framed by nine building blocks that outline all the elements that must be explored in order to develop business models.

Visual inquiry tools have been developed to facilitate a less linear and more creative and innovative process than traditional strategic management tools; they support a social design process in that they rely on both design techniques and visualization for collaboration (Comi \& Bresciani, 2017; Dym et al., 2005). According to Dalsgaard (2017), they allow one to approach and transform uncertain situations in which there are no straightforward answers by clarifying problems through exploration and sensemaking strategies. Also, such tools facilitate the formation of ideas and also hypotheses about how to address problems and experiment with these ideas in practice (Horn \& Weber, 2007). We compare these tools to traditional strategic management tools in Table 1.

Given the increasing number and use of visual inquiry tools, it seems crucial to accumulate knowledge regarding their development and evaluation. The lack of prescriptive knowledge for designing visual inquiry tools has become problematic because, without such knowledge, their development relies primarily on designers' intuition or is based on imitating existing popular tools such as the Business Model Canvas. Most developments have been carried out without a clear and rigorous conceptualization of the form and functions of the intended design. Thus, designers who wish to develop a visual inquiry tool can only rely on the apparent features and properties of other tools (Piirainen \& Briggs, 2011). For instance, several design science researchers have admitted to replicating the logic behind the Business Model Canvas without following prescriptive knowledge for their development (e.g., Campbell et al., 2017; ChandraKruse \& Nickerson, 2018). This motivates the question that drives our research project: How can we develop visual inquiry tools for specific strategic management problems?

Table 1. Comparison of Traditional and Visual Inquiry Tools

\begin{tabular}{|l|l|l|}
\hline Tool types & Traditional management tools & Visual inquiry tools \\
\hline $\begin{array}{l}\text { Problem-solving } \\
\text { approach }\end{array}$ & $\begin{array}{l}\text { Analytical and rational processes of } \\
\text { decision-making, planning, and } \\
\text { optimization. Deductive and inductive. }\end{array}$ & $\begin{array}{l}\text { Process of joint inquiry: exploring alternative hypotheses, } \\
\text { creative and iterative design. Abductive and inventive. Based } \\
\text { on design thinking techniques. }\end{array}$ \\
\hline Types of use & $\begin{array}{l}\text { Mainly verbal, use of tables and diagrams. } \\
\text { Mainly rational and objective. Lead by } \\
\text { organizing and planning. }\end{array}$ & $\begin{array}{l}\text { Mainly visual, use of sketching, and prototyping. Intensive } \\
\text { observation and wondering, challenging stereotypical } \\
\text { perception. Comfortable with ambiguity and uncertainty. }\end{array}$ \\
\hline Examples & $\begin{array}{l}\text { Porter's Five Forces, BCG growth-share } \\
\text { matrix, Strategic group maps. }\end{array}$ & $\begin{array}{l}\text { Business Model Canvas, Value Proposition Canvas, Team } \\
\text { Alignment Map, Project Canvas, Innovation Matrix, } \\
\text { Operating Model Canvas, Customer Journey Map, Portrait of } \\
\text { Design Essence, Market Opportunity Navigator. }\end{array}$ \\
\hline
\end{tabular}




\section{Method}

\subsection{Research Design}

To answer our research question, we theorized the knowledge accumulated within and across three DSR projects that resulted in the design of visual inquiry tools: the Business Model Canvas, the Value Proposition Canvas, and the Team Alignment Map. Given the lack of frameworks and processes for analyzing and theorizing multiple-project data in DSR, we used a hybrid approach between theorizing in DSR (Gregor \& Jones, 2007; Lee, Pries-Heje \& Baskerville, 2011; Mandviwalla, 2015; Meth, Mueller \& Maedche, 2015) and multiple-case analysis in the social sciences (Fereday \& Muir-Cochrane, 2006; Miles \& Huberman, 2010). We performed a within-project and crossproject analysis to capture, formalize, and compare the design knowledge that was acquired in the three projects. The design knowledge of interest concerns all the design intuitions, design decisions, principles of form and function, and descriptive knowledge that were used to understand the problems and design the corresponding solutions in each case.

Our analysis has three aims: (1) to outline the process of the development and accumulation of design knowledge within each project, (2) to abstract and theorize the design knowledge by analyzing the idiosyncrasies and commonalities across the three projects, and (3) to formalize the theorized design knowledge as a midrange design theory, which can serve as a foundation for future designers of visual inquiry tools. A design theory is a set of principles and knowledge that describe and guide the design of an artifact in order to attain a specific goal in the material world (Gregor \& Jones, 2007).

\subsection{Project Selection}

The three projects we selected represent three longitudinal DSR initiatives that have been undertaken separately (Table 2). We used the theoretical sampling criteria recommended by Eisenhardt (1989) to ensure comparison among the three projects. That is, we selected the three projects because (1) they are among the few widely recognized examples of tools that support a joint inquiry approach to solving specific strategic management problems, which is the target of our research question, and are also (2) designed based on theoretically sound and rigorous academic work using a DSR approach.

Besides their criticality, there were additional rationales for choosing these projects. Some of the coauthors were directly involved in the projects, which allowed for extensive access to data on the design process and design decisions, and aspects of the design knowledge have also been formalized in journal and conference publications. Also, the three projects were developed following DSR approaches. This illustrates the academic rigor with which the three research projects were conducted, in contrast to other similar tools that are designed primarily through designer intuition or imitation of existing tools. Also, the three artifacts were developed in close collaboration between academics and practitioners and were continuously refined based on evaluations in situated contexts. Finally, the search for specificities allowed us to have some variety, which increased the reliability of our design theory. The three projects contrast in that they address different strategic problems (business modeling and strategic innovation, value proposition design, and team alignment and project kickoff). Since each strategic management problem has its own set of challenges, this provided variety in our sample regarding the problems and the solutions that the design science researchers addressed.

\subsection{Presentation of the Three Projects}

\subsubsection{The Business Model Canvas Project}

In a business landscape characterized by complexity and uncertainty, in which business models demand the coordination of an increasing number of stakeholders (Teece, 2010), there needs to be a tool to understand, map, and share a firm's business logic. This was the logic behind the Business Model Canvas when it was designed (Figure 1). The Business Model Canvas defines business models as having nine components and presents these components via a visual template to facilitate the ideation, elaboration, and evaluation of business model ideas. The Business Model Canvas project spanned from 1999 to 2012.

The tool has attracted tremendous interest in practice; the tool designers claim that, globally, there have been 6 million downloads of the tool (Strategyzer, 2015). As of 2015, 1.5 million copies of the book Business Model Generation had been sold and more than 400 universities had used the Business Model Canvas for at least one course. In practice, the Business Model Canvas has become the quasi-standard for describing business models. Further, the impact of the Business Model Canvas is not limited to practice, evidenced by the 12,000 studies on Google Scholar that reference the book describing the tool.

\subsubsection{The Value Proposition Canvas Project}

Creating value for customers is a major challenge for organizations. One reason that a large majority of newly funded companies fail is because of poor product market fit (Feinleib, 2011). Finding the right value proposition is challenging since it requires testing of all hypotheses and strong empathy with customers. This is the design logic underlying the Value Proposition Canvas (Figure 2), which allows 
users to define the value proposition and frame it from the perspective of the relevant customer segments. It has two sides, composed of three blocks. These are presented on a visual template to facilitate the ideation, elaboration, and evaluation of a value proposition and its fit with its customer segment. The Value
Proposition Canvas project lasted from 2011 to 2014. By early 2018, the Value Proposition Canvas had been downloaded more than a million times. Also, the numerous requests for training and workshops evidence the extensive interest in this tool among practitioners.

Table 2. Overview of the Cases

\begin{tabular}{|c|c|c|c|}
\hline Tool & Business Model Canvas & Value Proposition Canvas & Team Alignment Map \\
\hline $\begin{array}{l}\text { Strategic } \\
\text { problem }\end{array}$ & $\begin{array}{l}\text { Business modeling and strategic } \\
\text { innovation }\end{array}$ & Value proposition design & $\begin{array}{l}\text { Team alignment and project } \\
\text { kickoff }\end{array}$ \\
\hline $\begin{array}{l}\text { Adoption and } \\
\text { use }\end{array}$ & $\begin{array}{l}\text { Adopted by } 6+\text { million people } \\
\text { worldwide, including startups, } \\
\text { SMEs, and large organizations for } \\
\text { business modeling, strategic } \\
\text { management, and competitor } \\
\text { analysis. }\end{array}$ & $\begin{array}{l}\text { Adopted by } 1+\text { million people } \\
\text { worldwide, including startups, } \\
\text { SMEs, and large organizations for } \\
\text { designing and testing different value } \\
\text { propositions and their fit with } \\
\text { potential customer segments. }\end{array}$ & $\begin{array}{l}\text { Adopted by teams in } 200+ \\
\text { organizations to manage } \\
\text { collaboration and project } \\
\text { kickoffs in organizations in } \\
\text { different sectors. }\end{array}$ \\
\hline $\begin{array}{l}\text { Secondary } \\
\text { data collection }\end{array}$ & $\begin{array}{l}\text { Cycle } 1 \text { (1999 to 2004): Design of } \\
\text { the Business Model Ontology } \\
\text { (Business Model Ontology) } \\
\text { - } 2 \text { instantiated case studies } \\
\text { - } 11 \text { semistructured interviews of } \\
60 \text { to } 90 \text { minutes with managers } \\
\text { and consultants } \\
\text { - } 5 \text { fifteen-week courses with } 30 \text { to } \\
60 \text { undergraduate students } \\
\text { - References: Gordijn et al. (2005); } \\
\text { Osterwalder \& Pigneur (2002); } \\
\text { Osterwalder (2004); Osterwalder, } \\
\text { Pigneur \& Tucci (2005). } \\
\text { Cycle } 2 \text { (2004 to 2008): Design of } \\
\text { the Business Model Canvas } \\
\text { - } 32 \text { one-day workshops and } \\
\text { seminars with practitioners } \\
\text { - } 4 \text { fifteen-week courses with } 30 \text { to } \\
60 \text { undergraduate students } \\
\text { - References: Fritscher \& Pigneur } \\
\text { (2009); Osterwalder \& Pigneur } \\
\text { (2010); Osterwalder \& Pigneur } \\
\text { (2013). } \\
\text { Cycle } 3 \text { (2008 to 2016): Design of } \\
\text { the Business Model Mechanics, the } \\
\text { iPad app, and the web app } \\
\text { - } 256 \text { two-day workshops and } \\
\text { seminars with management } \\
\text { practitioners and entrepreneurs } \\
\text { - Questionnaire to 1,300 users } \\
\text { - Semistructured interviews with } 35 \\
\text { users of } 2 \text { hours each } \\
\text { - } 8 \text { fifteen-week courses with } 30 \text { to } \\
60 \text { undergraduate students } \\
\text { - References: Fritscher ( } 2014) ; \\
\text { Fritscher \& Pigneur ( } 2014 a) ; \\
\text { Fritscher \& Pigneur (2014b). }\end{array}$ & $\begin{array}{l}\text { Cycle } 1 \text { (2011 to 2012): Design of } \\
\text { the conceptual model } \\
\text { - Literature review of customer } \\
\text { development and value } \\
\text { proposition design } \\
\text { - The jobs-to-be-done framework } \\
\text { had already been tested by Ulwick } \\
\text { (2005). } \\
\text { Cycle } 2 \text { (2012 to 2013): Design of } \\
\text { the Value Proposition Canvas } \\
\text { - Evaluation of the visual layout } \\
\text { with } 60 \text { practitioners and } 55 \\
\text { undergraduate students } \\
\text { - Design of the layout with a } \\
\text { seasoned visual designer } \\
\text { Cycle } 3 \text { (2013 to 2014): Stabilization } \\
\text { of the directions for use } \\
\text { - Evaluation of the Value } \\
\text { Proposition Canvas with } 100 \\
\text { practitioners } \\
\text { - Evaluation of the Value } \\
\text { Proposition Design (book) with } 60 \\
\text { practitioners } \\
\text { - Reference: Osterwalder et al. } \\
\text { (2014). }\end{array}$ & $\begin{array}{l}\text { Cycle } 1 \text { (2010 to 2014): } \\
\text { Design of the COOPilot } \\
\text { conceptual framework } \\
\text { - longitudinal cases of } 3 \\
\text { project teams in different } \\
\text { organizations } \\
\text { - } 3 \text { workshops with project } \\
\text { managers } \\
\text { - Reference: } \\
\text { Mastrogiacomo, } \\
\text { Misssonier \& Bonazzi } \\
\text { (2014). } \\
\text { Cycle } 2 \text { (2014 to 2015): } \\
\text { Design of the COOPilot } \\
\text { App } \\
\text { - } 4 \text { cases of project teams } \\
\text { in different organizations } \\
\text { - } 8 \text { one-day workshops } \\
\text { with project managers } \\
\text { - Reference: Avdiji (2018); } \\
\text { Missonier et al. (2014). } \\
\text { Cycle } 3 \text { (2015 to 2017): } \\
\text { Design of the Team } \\
\text { Alignment Map } \\
\text { - } 10 \text { cases of project teams } \\
\text { in different organizations } \\
\text { - } 11 \text { one-day workshops } \\
\text { with project managers } \\
\text { - Semistructured interviews } \\
\text { with } 7 \text { users } \\
\text { - References: Avdiji, } \\
\text { Missonier \& } \\
\text { Mastrogiacomo (2015); } \\
\text { Avdiji \& Missonier } \\
\text { (2018); Avdiji (2018); }\end{array}$ \\
\hline
\end{tabular}




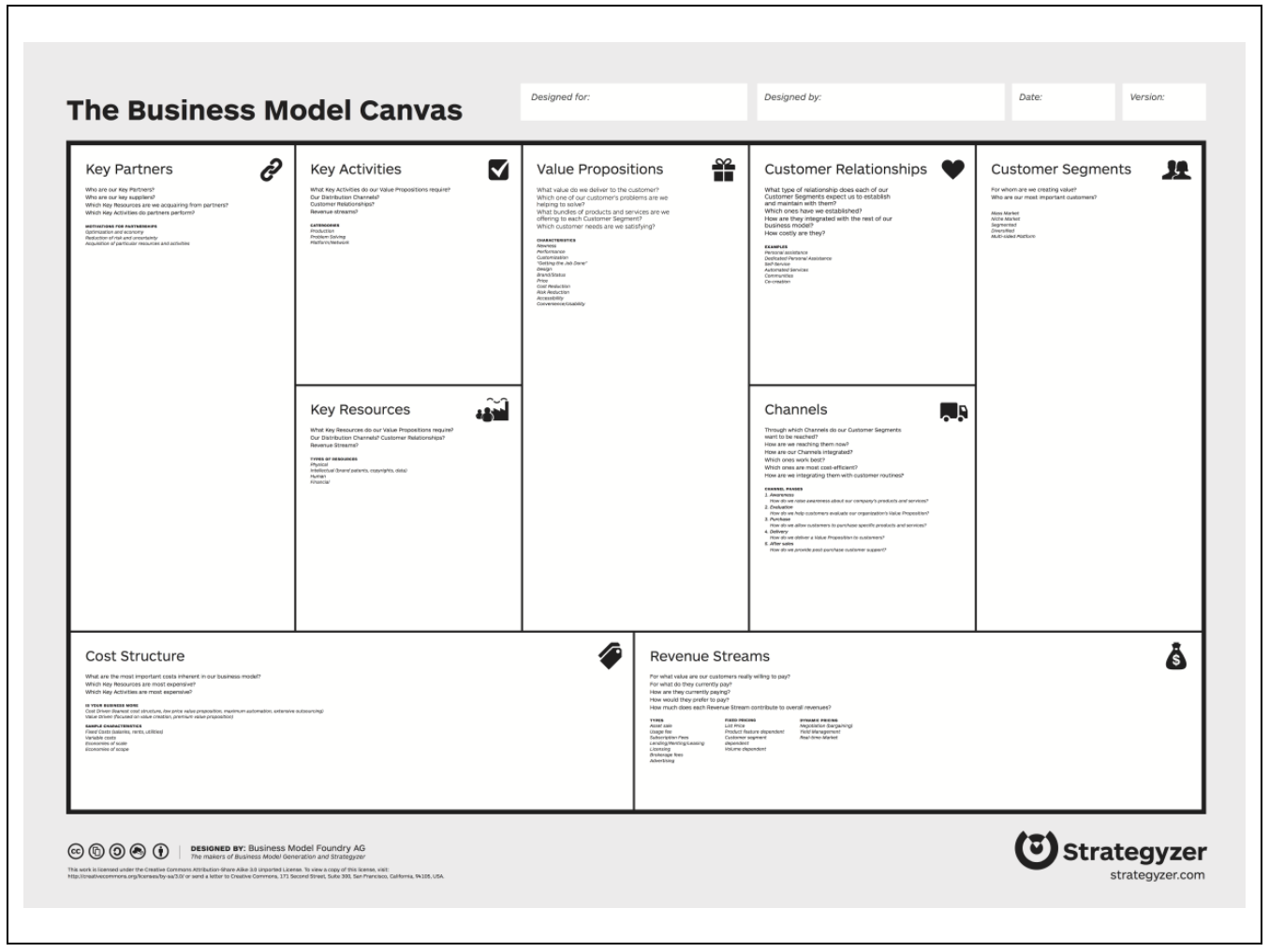

Figure 1. The Business Model Canvas

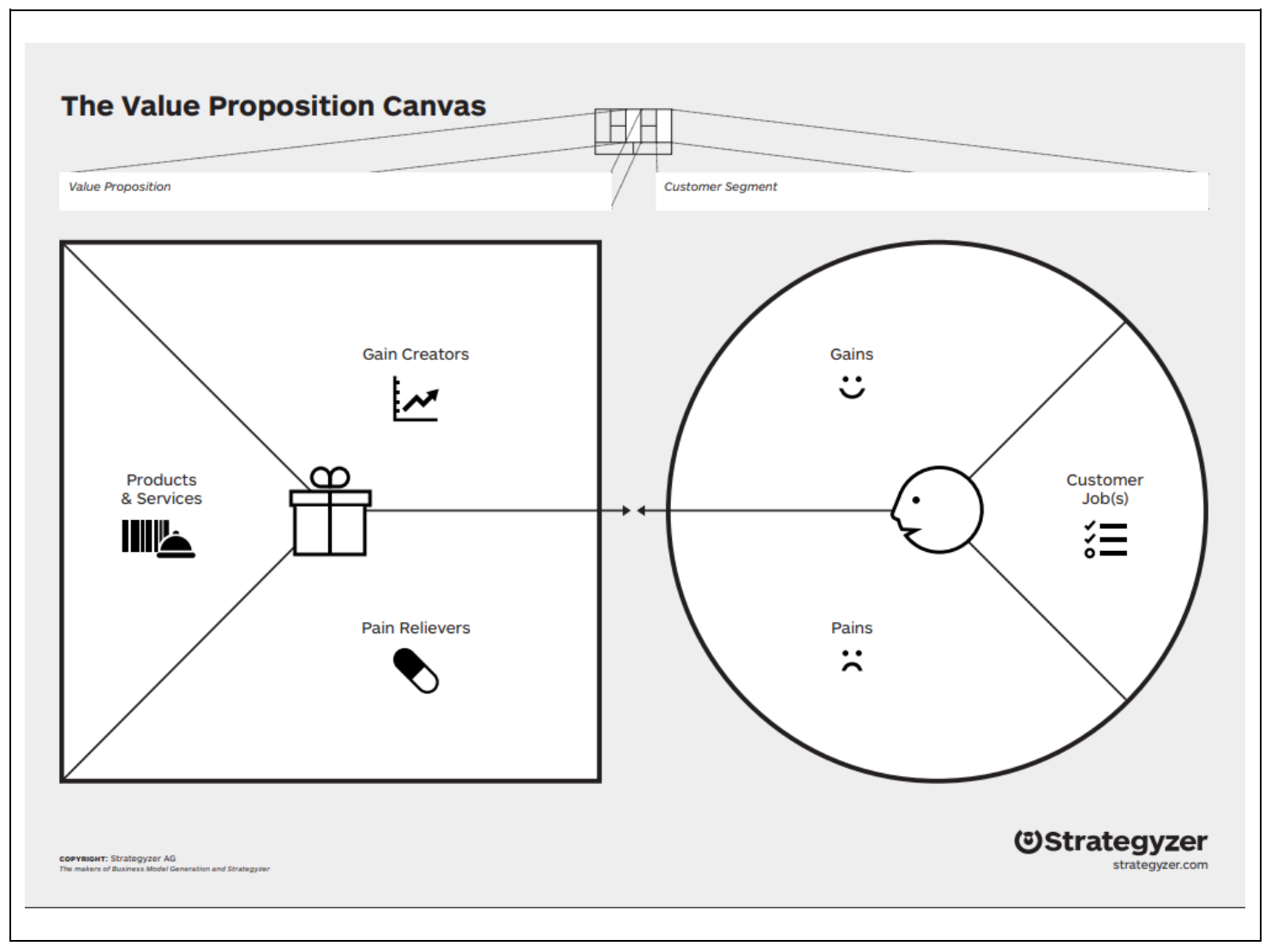

Figure 2. The Value Proposition Canvas 


\subsubsection{The Team Alignment Map Project}

In complex and unpredictable environments, project team members need to regularly coordinate their efforts (Espinosa, Cummings, Pearce \& Wilson, 2002). In this regard, traditional coordination mechanisms have proven incomplete or often ineffective (Okhuysen \& Bechky, 2009; Mintzberg, 1979; Sosa, Eppinger \& Rowes, 2004). Insights from the literature and requests from practitioners led to the design of the Team Alignment Map (Figure 3), which is a collaborative tool used by teams during meetings to coordinate effectively. This tool reverses the logic of coordination: it allows team members to design their collaboration in a highly iterative way and requires the participation and ownership of all participating team members. The Team Alignment Map project lasted from 2010 to 2017.

The Team Alignment Map has been presented at conference proceedings and in journal articles but has also been used extensively by project-based teams in various industries and sectors, such as manufacturing, health, IS, and innovation. The Team Alignment Map has also attracted interest from a wide array of organizations; the design team has received more than 200 requests for training. In practice, it is extensively used by project managers and management consultants.

\subsection{Data Collection}

To collect the data for our analysis, we followed common recommendations for qualitative research based on case studies (Eisenhardt, 1989; Miles \& Huberman, 2010; Siggelkow, 2007), and relied on an extensive set of data that included multiple sources (see Table 2). In the three DSR projects, we gained firsthand knowledge through our strong involvement and participation in these projects (some co-authors were members of the DSR team of one of the three projects). Semistructured interviews with a member of the DSR project served as primary data sources, providing insights into how the project was conducted, how the artifacts were designed over different iterations, and what different problems and solutions the project addressed. The other main source of information was data collected from workshops run by the design teams. During these workshops with management practitioners, the design teams gathered data from observations, interviews, and questionnaires (see Table 2) in order to evaluate, refine, and transform the artifacts.

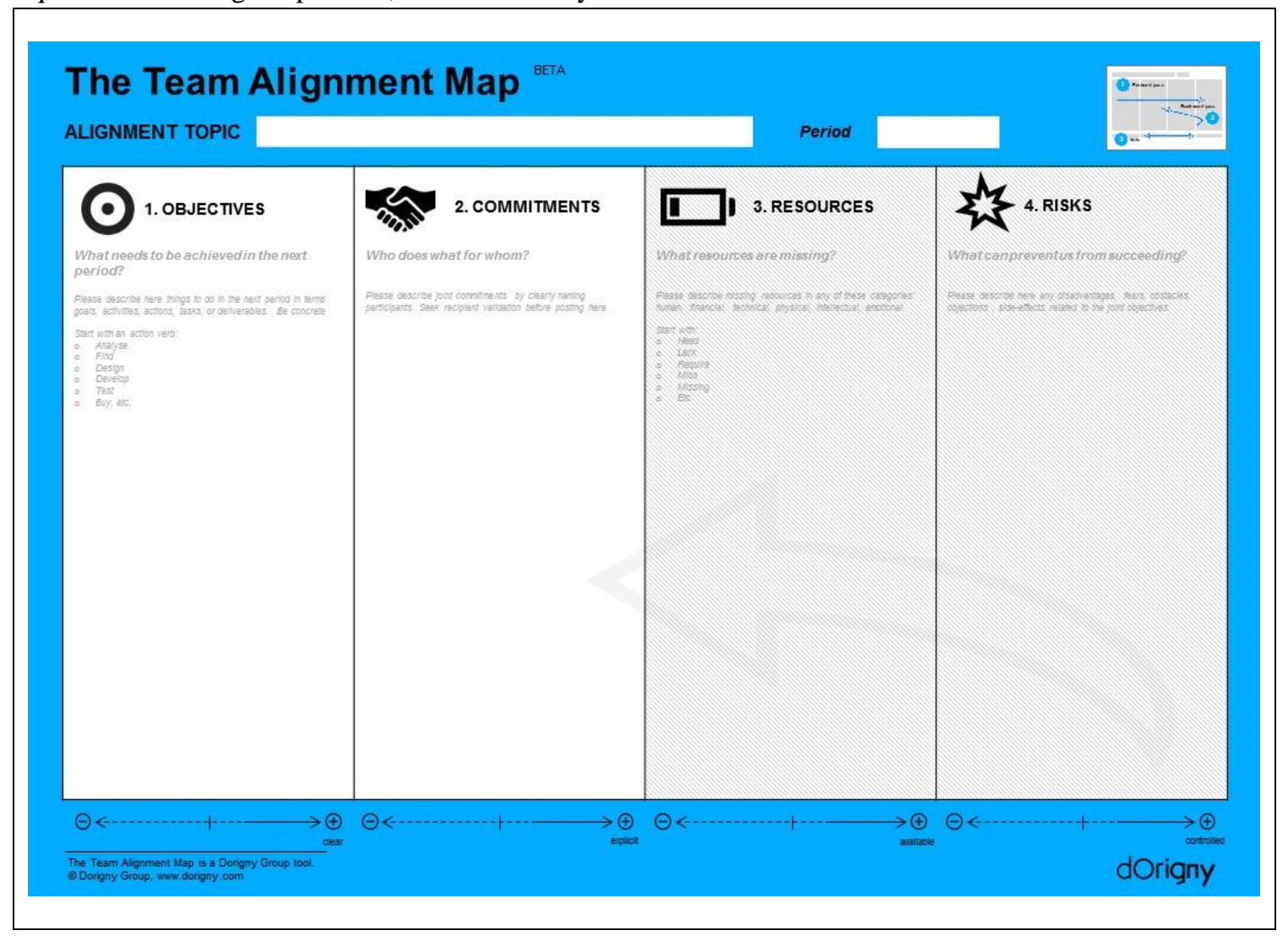

Figure 3. The Team Alignment Map 
For triangulation purposes, we also relied on the design knowledge explicitly formalized in 21 academic publications by the design team members (we ignored publications in which there was no analysis of the problem- or solution space, focusing instead on those in which artifacts were evaluated and design knowledge was explicitly formulated, thus), including 2 books, 8 sets of course materials, 16 workshop presentations, 4 documents for practitioners, and 4 news articles by the design teams.

\subsection{Data Analysis}

Our analysis consisted of within-project and crossproject analyses. Since the literature on DSR provides little insight into the methodological approaches to theorize design knowledge across multiple cases, we addressed this gap by bridging the frameworks and processes for knowledge formalization in DSR (Gregor \& Jones, 2007; Lee et al., 2011; Mandviwalla, 2015; Meth et al., 2015) with multiple case analysis methodologies in the social sciences (Fereday \& MuirCochrane, 2006; Miles \& Huberman, 2010). Specifically, we performed within-project and crossproject analyses around two primary activities (Figure 4): (1) analyzing the knowledge accumulation and evolution of design knowledge within each project, (2) theorizing the design knowledge across all projects and formalizing it as a design theory. These two activities allowed us to analyze the commonalities and differences among the three projects in order to develop a midrange theory (Offermann, Blob \& Bub,
2011). These activities were not conducted sequentially or in isolation; we constantly moved between Activity 1 and Activity 2 to ensure that the design theory was reflected in each empirical project (Ragin, 1994; Mueller \& Urbach, 2013).

To conduct these two main activities, we referred to Lee et al.'s (2011) framework for theorizing design knowledge process (Figure 5) and Meth et al. (2015). The framework by Lee et al. (2011) helped us to define the level of abstraction of the design knowledge on which we focused our analysis and the sequence of analyzing these different levels of abstraction. While Lee et al. do not specify an entry point for their process, they do distinguish between the abstract and instance domains. We chose to start with the instance domain because instance design knowledge is easier to identify, and then proceeded to the abstract domain. In the instance domain, a particular solution is designed or registered for a specific instance problem. The abstract domain denotes a generalized (rather than particular) problem class that is addressed by searching for an abstract solution. Within each level of abstraction, Meth et al. (2015) provide the analytical frames for the different design knowledge types we needed to identify. They distinguish different design knowledge types that can be captured and formalized (design requirements, design features, and design principles). In our data analysis, Activity 1 (withinproject analyses) refers to the instance domain and Activity 2 (cross-project analyses) refers to the abstract domain (Figure 4).

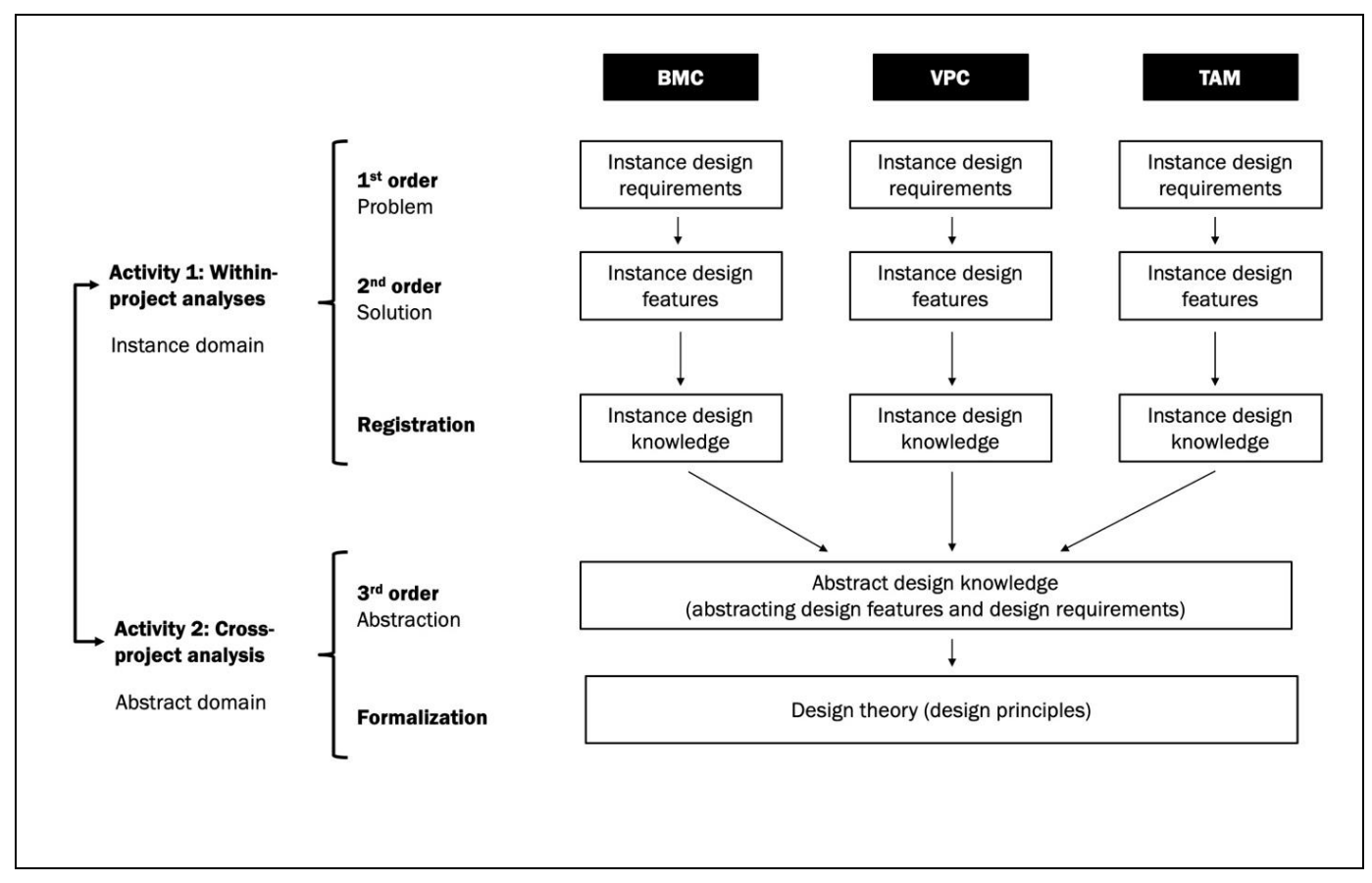

Figure 4. Data Analysis Process 


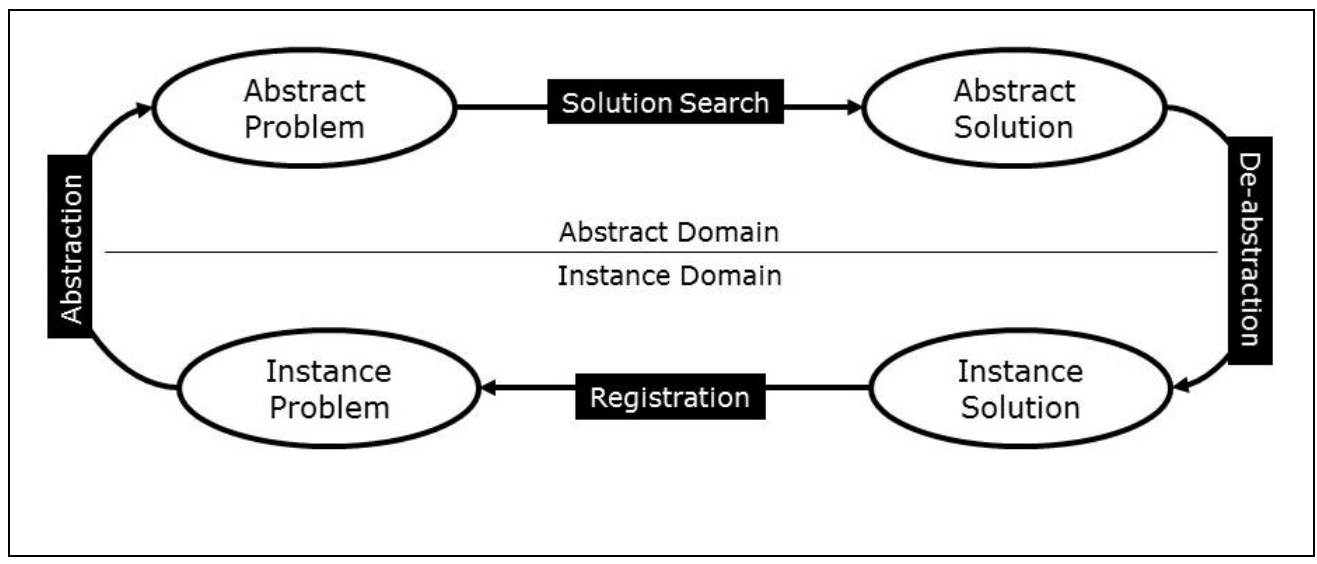

Figure 5. Process of Theorizing Design Knowledge by Lee et al. (2011)

\subsubsection{Activity 1: Within-Project Analysis of Design Knowledge Accumulation and Evolution}

We first performed within-project analyses of the three DSR projects (Figure 4). Our data analysis started with what Miles and Huberman (2014) term data condensation. During this stage, we sought to simplify and abstract the raw data within each project in order to make sense of the amount of data. To do this, we performed a thematic analysis (Boyatzis, 1998), following both Lee et al.'s (2011) framework and the design knowledge types differentiated by Meth et al. (2015). That is, we first singled out the instantiated problems addressed for each project. These correspond to the (instance) design requirements that the researchers addressed in the three projects. Design requirements outline the generic requirements that should be met by the designed solution (Meth et al., 2015). In that sense, they pertain to the problem domain since they outline the problems addressed by the designed solution. This is equivalent to the clustering of data into first-order themes in the social sciences (Fereday \& Muir-Cochrane, 2006).

After our data had been arranged according to the three different design requirements in each project, we identified the main artifacts (instance solutions) that were developed for each requirement. This allowed us to identify three problem-solution cycles in each project. Within these cycles, we identified the (instance) design features of each artifact, which represent the characteristics of the designed solution (Meth et al., 2015). These problem-solution cycles guided our data condensation process (Miles \& Huberman, 2014) and helped us sort, focus, and organize the considerable amount of data from each project.

To identify and analyze these different problemsolution cycles (i.e., the instantiated design requirements and the related instantiated design features), we proceeded by iterating between the collected secondary data (as shown in Table 2) and the insights of the co-authors involved in the design projects. At first, the design science researchers involved in the project were interviewed by another coauthor who was not part of the project. The semistructured interviews related the history of the project and outlined the instantiated problems and solutions developed throughout the projects. During the interviews, we followed Mandviwalla's (2015) recommendations to compare the stabilized versions of the visual inquiry tools (e.g., the Business Model Canvas in its current form) with previous prototypes (e.g., the printed Business Model Ontology used with sticky notes). This allowed us to highlight the discarded insights and investigate why the stabilized design features were more relevant in addressing the design requirements.

The interviews were then transcribed by the interviewers and validated by the interviewees. The interviewer also complemented the identified cycles with the analysis of the design knowledge that had already been formalized by the project researchers in our secondary data sample (Table 2). That is, the interviewer referred to the publications and training materials developed by the researchers since some of these specifically mentioned the most important design features and requirements of the artifacts. Then, to ensure the reliability of the analysis, the other two coauthors verified the first-order and second-order thematic analysis of the design knowledge accumulation (i.e., the problem-solution cycles, as displayed in Tables 3, 4, and 5) for each project by ensuring that the analysis corresponded to what was formalized in the secondary data sample. This verification was complemented by discussions between all authors for the purpose of developing an "intersubjective consensus" (Miles \& Hubermann, 2010) through paying particular attention to the 
principles of suspicion and multiple interpretations as defined by Klein and Myers (1999).

Finally, for all three projects, we performed registration, in the sense of Lee et al. (2011). We identified the design knowledge that had been accumulated in terms of design features for each design requirement, i.e., for each problem-solution cycle (see Figures 7, 8, and 9). Since our main concern in Activity 1 was to ensure that the design knowledge identified was exhaustive enough (i.e., that key design features and design requirements were not left out), our data analysis ended when all the design features documented in the secondary data were covered for each project and when the designers of the visual inquiry tools considered the analysis to be exhaustive. There were iterations and discussions between the designers in each project and the other co-authors, which ensured that the design knowledge was intelligently formalized and that the relationships between design features and design requirements were made explicit.

\subsubsection{Activity 2: Cross-Project Analysis to Theorize the Design Knowledge}

In a second stage, we performed a cross-project analysis. We first aggregated the design knowledge that was accumulated within each project (Appendix Figure A1), which allowed us to identify differences and regularities. The regularities were used as the main input for the design theory because their occurrence in the three projects suggests that they would also apply to projects beyond our sample. A design feature was considered for inclusion in the design theory if it appeared in all three projects. The differences allowed us to either rule out design knowledge that was specific to certain projects (e.g., the Team Alignment Map project developed an evaluation solution in the form of a mobile app, while the Business Model Canvas project led to the development of a computer-aided design / CAD solution) or formulate certain aspects of the design theory with more flexibility (e.g., problems that were addressed in the cycles of each project emerged in a different order, which we addressed by avoiding a set development plan). Both regularities and differences were discussed using investigator triangulation (Patton, 2002). This cross-project comparison resulted in abstract design features that were applicable across the three projects (Figure A1) and are comparable to third-order themes in qualitative research (Fereday \& Muir-Cochrane, 2006). We formulated the abstract features in such a way that they did not include any situated specificities of the artifacts.
For the last step of our cross-project analysis we adapted the abstract design features to Gregor and Jones's (2007) framework for presenting design theories. In this step, we performed three specific analyses. First, we translated the abstracted design features that were common across all projects into design principles of form and function, following the guidelines by Chandra, Seidel, \& Gregor (2015). Design principles describe a means-ends relationship in the form of prescriptive statements that outline how abstract design features address the design requirements (Meth et al., 2015). Second, we translated the design features that were not common across all projects into principles of mutability for visual inquiry tools. Finally, we identified the metarequirements of the design theory by analyzing the similarities of the problems (design requirements) for which the three visual inquiry tools were used. By analyzing these characteristics, we defined the purpose and scope of our design theory as applying to strategic management problems, as outlined in the literature review.

To ensure the reliability and credibility of our analysis, we used investigator triangulations (Patton, 2002). Each co-author conducted each step of our crossproject analysis to check the consistency of the analysis. Also, our analysis was scrutinized by two independent and external researchers who are familiar with DSR and have developed visual inquiry tools. The rationale was to identify additional design principles that they had implicitly used in their various projects that we may have overlooked.

\section{Project Analyses}

We now present how the design knowledge for visual inquiry tools accumulated and evolved across the three projects. We structure the presentation of the findings in a temporal order (Figure 6) and present the knowledge accumulation and replication over time. We first present the development process of the Business Model Canvas and outline the design knowledge that was accumulated throughout its development. We then relate how the designers of the Business Model Canvas transferred the design knowledge they acquired into the design of the Value Proposition Canvas. Finally, we discuss the design knowledge that was common and different in the two projects. Using the knowledge the researchers obtained in the two projects, they conducted a workshop (the Business Design Summit) to share their experience and knowledge and help other management thinkers develop visual inquiry tools for their domains of expertise. 


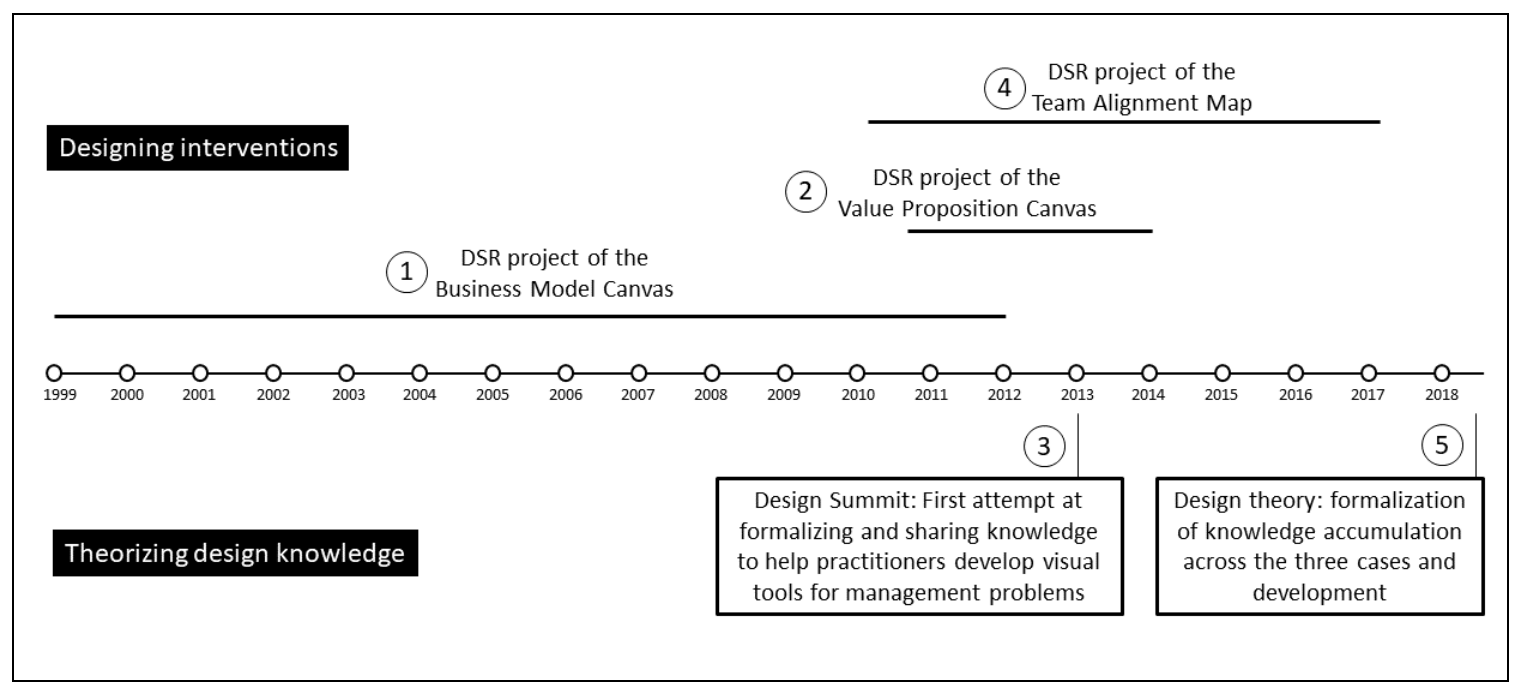

Figure 6. Timeline of the DSR Projects and the Theorization Episodes

Table 3. Summary of the DSR project for the Business Model Canvas

\begin{tabular}{|c|c|c|c|}
\hline Cycle & $\begin{array}{l}\text { 1: Defining the } \\
\text { management concept }\end{array}$ & $\begin{array}{l}\text { 2: Translating the management } \\
\text { concept into a tool for joint } \\
\text { inquiry }\end{array}$ & $\begin{array}{l}\text { 3: Stabilizing directions for joint } \\
\text { inquiry and developing methods } \\
\text { for evaluation }\end{array}$ \\
\hline Period & 1999 to 2004 & 2004 to 2008 & 2008 to 2016 \\
\hline Problem domain & $\begin{array}{l}\text { For an entrepreneur, the } \\
\text { business plan is not the } \\
\text { best tool to provide a } \\
\text { coherent description of his } \\
\text { or her startup }\end{array}$ & $\begin{array}{l}\text { The Business Model Ontology is } \\
\text { helpful to ask the right questions } \\
\text { but not intuitive enough for } \\
\text { codesigning a business model }\end{array}$ & $\begin{array}{l}\text { Users of the Business Model } \\
\text { Canvas have difficulties extracting } \\
\text { hypotheses about the business } \\
\text { model and evaluating them }\end{array}$ \\
\hline Design requirement & $\begin{array}{l}\text { How to define a business } \\
\text { model? }\end{array}$ & $\begin{array}{l}\text { How does one codesign into a } \\
\text { business model? }\end{array}$ & $\begin{array}{l}\text { How does one test and evaluate a } \\
\text { business model? }\end{array}$ \\
\hline $\begin{array}{l}\text { Solution domain } \\
\text { (artifacts) }\end{array}$ & $\begin{array}{l}\text { - Business Model } \\
\text { Ontology }\end{array}$ & $\begin{array}{l}\text { - } \text { Business Model Canvas } \\
\text { - Business Model Generation } \\
\text { (book) }\end{array}$ & $\begin{array}{l}\text { - Business Model Mechanics } \\
\text { - iPad App }\end{array}$ \\
\hline $\begin{array}{l}\text { Joint inquiry } \\
\text { technique (Steen, } \\
\text { 2013) }\end{array}$ & - Defining & $\begin{array}{l}\text { - Ideating } \\
\text { - Prototyping }\end{array}$ & $\begin{array}{l}\text { - Testing } \\
\text { - Implementing }\end{array}$ \\
\hline
\end{tabular}

The Business Design Summit validated practitioner and scholarly interest in design guidance regarding the design of such tools. However, only a few visual inquiry tools were actually developed by attendees following the workshop, which punctuated the need to refine and extend the design knowledge to make it more replicable. Thus, we also discuss the development of the Team Alignment Map, which was independent of the other two tools. Analyzing the design knowledge accumulated across the three projects allowed us to formulate the design theory for visual inquiry tools, which we present at the end of this section.

\subsection{The Business Model Canvas: Generating the Foundational Design Knowledge for Visual Inquiry Tools}

There were three main cycles in the Business Model Canvas project, each addressing a different problem type (design requirement) and research questions relating to business modeling (Table 3), which reflect the particularity and novelty of the Business Model Canvas. Each cycle corresponds to the development of a solution to support practitioners in using inquiry techniques for business modeling. Our description of these cycles is oriented toward the explanation of (1) the evolution of the problems faced by practitioners regarding business modeling, (2) the solutions (artifacts) suggested by the design science researchers for addressing these problems, and (3) the design knowledge accumulated for each of the cycles. At the end of this subsection, we provide a summary of the design knowledge accumulated throughout the entire project.

\subsubsection{Cycle 1 (1999 to 2004): Defining the Management Concept}

Problem domain: The DSR project started in the era of the dotcom bubble and the emergence of internet 
ventures. In that context, a need to define and describe new business models that were made possible by the internet arose. Investors and analysts required new means to evaluate the potential value of the increasing number of startups. To do this, startup founders increasingly made use of concepts such as business plans and business models to describe, compare, and assess the ways in which their e-business ventures could create value. After interacting with and supporting entrepreneurs in French-speaking Switzerland, the two initiators of the projectAlexander Osterwalder and Yves Pigneur-concluded that entrepreneurs would mostly rely on the business plan concept to describe their ventures. This approach proved inefficient for describing the logic of these businesses, since most entrepreneurs simply completed business plan documents without a coherent and clear depiction of all aspects of their organization. Further, most of their efforts were devoted to forecasting their company's financial potential, with less attention paid to customers, company infrastructure, and proposed business value. Thus, the researchers developed a DSR project to find an answer to the question: How do we define business models? In answering this question, they sought to develop a means to improve how entrepreneurs reflected on their ventures.

Solution domain: The researchers' intuition for addressing this problem was to define a set of questions for entrepreneurs to answer. In this cycle, they employed an ontology of all the domains required for defining an organization's business model, which thus motivated the questions that the entrepreneurs would need to answer in describing their venture. The result of this was the development of the Business Model Ontology contained in Osterwalder's (2004) doctoral dissertation (Figure A2).

The Business Model Ontology was designed after performing an extensive literature review and consolidating the dispersed body of knowledge on business modeling. The researchers identified all the concepts that were used in the business literature to describe business models and then grouped them into categories according to their similarities. For instance, various constructs related to the market value offered by the organization were grouped under value proposition-e.g., product/market scope (Hamel, 2000), value stream (Mahadevan, 2000), and product and service offered (Applegate \& Collura, 2001). The sorting and categorization of these constructs were based on the four perspectives of the Balanced Scorecards (finance, customers, infrastructure, and learning), resulting in nine components that occurred most frequently in previous studies (Osterwalder, 2004, p. 129). Clear and precise definitions were then provided for each domain. Questions for each of the constructs of the Business Model Ontology were defined to guide the reflection of its users and included questions such as "Who are your clients?" for the customer component or "What value do you propose?" for the value proposition component.

It is important to note that the researchers did not have the Business Model Canvas in mind when developing the Business Model Ontology. The purpose at that time was to provide a basic common language and set of questions that could be used by cross-boundary individuals to communicate and reflect on business models. The researchers ran workshops on the design of the Business Model Ontology, during which they used various visual depictions of the Business Model Ontology to introduce it to practitioners. The researchers described the business models of existing and well-known organizations through displaying nine boxes (representing the nine elements of the Business Model Ontology) and filling them in with sentences describing the box elements.

Design knowledge accumulated: The major design knowledge that the design science researchers accumulated during the first cycle was the Business Model Ontology and the need to define the management concept of interest through a conceptual framework. Given that the nascent literature on business modeling had accumulated in dispersed bodies, it was important to identify the elements, attributes, and relationships that characterize business models. The value and novelty of the Business Model Ontology lie in the different conceptualization of business modeling that its designers provided. They placed greater emphasis on the strategic level of business modeling compared to other approaches, which were mainly concerned with modeling company processes (e.g., Gordijn, Osterwalder \& Pigneur, 2000).

In Osterwalder's (2004) dissertation, several design decisions regarding the principles of form and function were made in order to ensure the quality of the definition of the management problem. First, the identification and definition of the nine components of the Business Model Ontology were based on academic justificatory knowledge. The Business Model Ontology was refined twice after evaluating it with practitioners and applying it to concrete case studies. Second, the researchers explicitly decided to keep the level of detail of the Business Model Ontology parsimonious so that it could provide a common language for practitioners who are not experts in the domain of business modeling. Third, they made sure that the nine elements of the Business Model Ontology were sufficient to cover all aspects required for describing an organization and had clear and delimited definitions. In that sense, their ontology diverged from the traditional approach of describing a phenomenon as exhaustively as possible. They made the design decision that their ontology would remain at a strategic level. It is important to note that one of the goals that 
motivated them to avoid a prohibitive level of detail was to provide a way of defining an organization that would be more intuitive than traditional business plans.

\subsubsection{Cycle 2: Translating the Management Concept into a Strategic Tool for Joint Inquiry}

Problem domain: The need to create the Business Model Canvas emerged during the workshops that the researchers ran with practitioners. The researchers noticed the limitations of the Business Model Ontology when using it during workshops and training. The Business Model Ontology proved valuable to describe and illustrate existing business models during workshops. However, when asked to design the business models of the practitioners' own organizations, the researchers simply changed the size of the boxes of the Business Model Ontology and typed in a new description for each box. The researchers realized that this model was impractical for designing potential future business models of organizations in real time because the Business Model Ontology had mainly been conceived as a framework for describing existing business models. Therefore, they developed a new research question for their design science project: How can business models be codesigned?

Solution domain: The answer to this question led the researchers to intuitively develop the Business Model Canvas in order to recreate a design space that reflected the conceptual model of the Business Model Ontology. Thus, the Business Model Canvas integrates the nine elements of the Business Model Ontology as empty building blocks. The relationships of the Business Model Ontology are replaced by the physical proximity of the building blocks. For instance, the value proposition is delivered to customer segments through an organization's relationships with its clients and through its channels. In 2006, the researchers added icons to clarify the building blocks through visual metaphors that made the masked relationships between the building blocks explicit.

When defining the directions for using the Business Model Canvas, the researchers turned to the work of Boland and Collopy (2006), which they had just discovered at the time, and which describes design thinking techniques that could be applied to management to increase collaboration and innovation within organizations. They focused their efforts on four of the five design thinking techniques that are outlined in Boland and Collopy's work, namely ideation, visual thinking, prototyping, and storytelling. While visual thinking was addressed by the visual form of the Business Model Canvas, the other design thinking techniques were translated into directions for use. To ideate and prototype different business models, the researchers suggested the use of sticky notes on which practitioners wrote different potential solutions for the nine building blocks. As these can easily be added, removed, amended, and displaced, it facilitated the emergence of ideas and the creation of prototypes. The designers also added a set of questions for each building block in one of the early versions of the Business Model Canvas to stimulate ideation (Figure 1). For storytelling, the researchers emphasized the role of the relationships between the building blocks of the Business Model Canvas. The story of a business model would have an entry point and continue through the elements of the proximal building blocks until all elements were covered.

While defining these design thinking techniques, the researchers started to consider writing the Business Model Generation book to formalize the explanation and directions for use of the Business Model Canvas. In the book, they provide illustrations with case studies to clarify the logic of the Business Model Canvas and present existing patterns of similar business models. They describe the three different directions for use and their rationale. The book was the first to provide both techniques for design thinking and the tool that supported it. In fact, at that time, most developments only addressed one of these aspects. Therefore, the book represented a unique value proposition at a time when design thinking and business models were gaining momentum in management practices.

Design knowledge accumulated: The reasons behind the rapid adoption of the Business Model Canvas related to several design decisions regarding form and function. Regarding form, the Business Model Canvas proved more valuable than the different visualizations of the Business Model Ontology, as it represented the elements of the Business Model Ontology as empty design spaces in which teams of practitioners could easily try out different ideas for their business models. The design spaces and the sticky notes provided a material support that allowed practitioners to visually and materially ideate on the business models. Second, the relative simplicity and ease-of-use of the tool were facilitated by the visual metaphors and icons, as well as the parsimonious number of building blocks (number of elements in the Business Model Ontology by extension).

Regarding the function, the researchers sought some harmony between the form of the Business Model Canvas and the three directions for use, namely the three design thinking techniques of ideation, prototyping, and storytelling. The empty design spaces and the questions for the nine building blocks allowed practitioners to easily ideate. The conjunction of using sticky notes and the empty design spaces facilitated the process of trying out different prototypes. Finally, the physical proximity between the related building blocks, along with the visual markers of sticky notes, provided a visual and fluid means of presenting a business model. 


\subsubsection{Cycle 3: Stabilizing the Directions for Use and Developing Methods for Evaluation}

Problem Domain: In the final cycle of the DSR project, the rapid and extensive adoption of the Business Model Canvas drove a voluminous demand for workshops and presentations. In this cycle, the researchers moderated 256 workshops with more than 5,000 practitioners. The feedback from the practitioners and their observation of the use cases demonstrated that the directions for use needed to be more explicit. A large number of practitioners used the Business Model Canvas as a checklist, using the nine building blocks as a list of aspects they needed to consider when designing a business model, without necessarily paying attention to the relationships between the solution elements and building blocks. For instance, practitioners might define a certain stream of revenue without relating it to a client segment. In addition to this type of inadequate use, the researchers noticed that the Business Model Canvas did not provide any means to evaluate and test the business models that were designed. This lack needed to be addressed because most design thinking approaches stress the need to evaluate and test the various solutions that practitioners elaborate (e.g., Boland \& Collopy, 2006; Buchanan, 2002). Therefore, the researchers sought to answer the question: How can business models be tested and evaluated?

Solution domain: The researchers developed the Business Model Mechanics, an instruction book that explicitly described the dynamics of the building blocks and provided several directions for use to ensure that these relationships were reflected in use. For instance, they suggested using color coding (i.e., sticky notes with the same color) to relate certain building blocks, and emphasized that no building block should be left with orphan elements (i.e., elements that are not connected to elements in other building blocks). These directions for use reflected the best practices for using the design thinking techniques associated with the Business Model Canvas.

To address the lack of support for testing and evaluating hypotheses about the business models, the designers took inspiration from Blank's (2013) work on customer development and lean startup. They grouped the building blocks according to Blank's four dimensions: feasibility, desirability, viability, and adaptability. This visual metaphor outlined the testing categories that the elements of the building blocks fell into. For instance, the viability hypothesis would be met if practitioners recognized that the elements in the Revenue Streams building block were more prominent than those in the Cost Structure block. The designers later developed testing cards to use for all the elements in the Business Model Canvas
The researchers also built on their background in IS to anticipate the potential of a CAD solution. Tzonis (2006) already mentions the potential benefits of applying techniques from architecture to management. Therefore, the researchers developed an iPad app and a software-as-a-service (SaaS) application, which have been downloaded and accessed more than 150,000 times. The SaaS application allows users to design business models and provides guidance on how to test the main hypotheses regarding the elements that users put in the software (Figure A3). The development of the application also marks the launch of the Stragyzer spinoff, which is the company that now manages the commercialization of the Business Model Canvas and the Value Proposition Canvas.

Design knowledge accumulated: This design cycle, along with its evaluation, confirmed the efficacy of the Business Model Canvas (it supports a process of design thinking for business modeling), effectiveness (the components of the tool are easy to understand), elegance (the tool is visually attractive and easy to use), ethicality (the tool supports morally correct transformation), and efficiency (the directions for use improve the jointinquiry process). Evaluation results confirmed the validity of these five propositions. Interestingly, the results also outlined 14 different uses of the Business Model Canvas, some of which had not been identified by the practitioners, suggesting that the tool was flexible in ways that were not anticipated (e.g., using the Business Model Canvas to understand competition or set numerical objectives).

In addition, the intuition that the directions for use of the Business Model Canvas should also address testing and evaluation was confirmed by the large adoption of the CAD applications, which highlighted the need to cover the whole spectrum of design thinking techniques when designing business models. The limitations of the paperbased Business Model Canvas suggested that the most appropriate means to test and evaluate solutions is through CAD tools, thus another form and artifact.

\subsubsection{Summary of the Design Knowledge Accumulated Throughout the Project}

In summary, the design knowledge (DK) that was accumulated across the three design cycles relates to the need to (1) develop an ontology to understand the management problem of interest and outline its main constituents (DK1.1 to 1.5 in Figure 7), (2) represent the Business Model Ontology through a shared visualization that allows for joint inquiry using sticky notes (DK2.1 to 2.5; DK3.5), (3) the need to develop directions for use based on design thinking (joint inquiry) techniques for effective exploration and prototyping (DK2.6, 3.2, and 3.4), and (4) the use of CAD to improve the evaluation of the business models (DK3.3 and 3.6). 


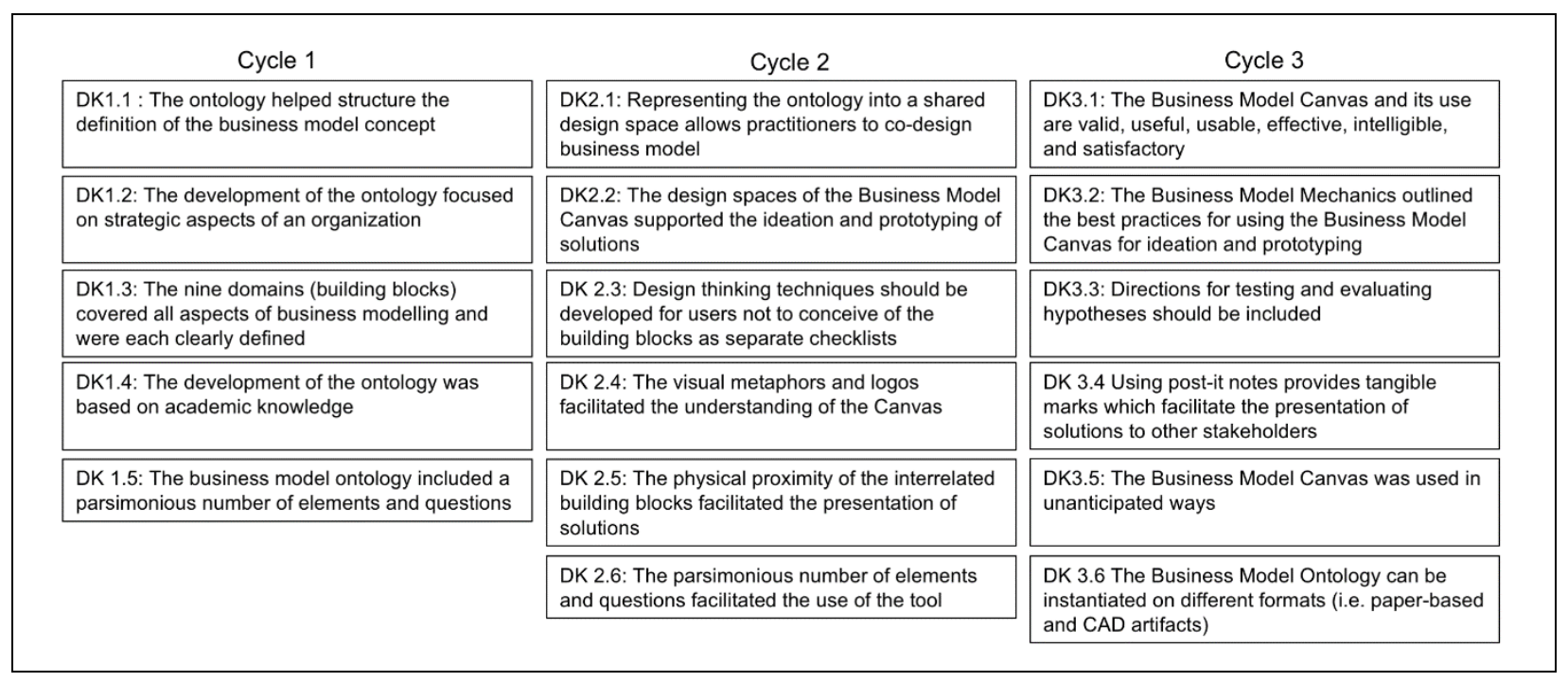

Figure 7. Design Knowledge Accumulation for the Business Model Canvas

\subsection{The Value Proposition Canvas: Replicating and Adapting the Design Knowledge into a New Visual Inquiry Tool}

The designers of the Business Model Canvas sought to replicate the knowledge they acquired by developing the Value Proposition Canvas. Thus, the researchers undertook a three-cycle DSR project (Table 4). They first developed the conceptual model, which they instantiated into a visual inquiry tool, and then developed directions for use. Notably, the development followed the same process as the development of the Business Model Canvas, but was completed in a significantly shorter amount of time. As the researchers had already accumulated knowledge on how to design a visual inquiry tool, they could more easily anticipate the design activities that needed to be performed.

\subsubsection{Cycle 1: Defining the Management Concept}

Problem domain: The need to design a new tool specifically for the value proposition building block became apparent during workshops and training with the Business Model Canvas. In several situations, the designers noticed that participants devoted a lot of effort and time to defining the value proposition and focused less on the other building blocks of the Business Model Canvas. This highlighted the need for practitioners to have a tool specifically dedicated to the codesign of value propositions. Therefore, the researchers first questioned: How can a value proposition be defined.

Solution domain: In the first cycle, the designers aimed to define the problem of designing value propositions. The designers had already defined the elements of the value proposition building block in Osterwalder (2004). However, they amended the conceptual framework after coming across the concept of "jobs to be done" that was first coined by Ulwick (2005). Ulwick's phrasing was close to the definition used in Osterwalder (2004) but it was oriented more toward the design thinking approach that the researchers sought for the Value Proposition Canvas. Since one activity in design thinking involves empathizing with the stakeholder, thinking in terms of jobs to be done and gains and pains would be more intuitive than evaluating value and the price of the product. The designers thus developed a conceptual framework that linked the value proposition and the customer segment building blocks (Figure A4).

Design knowledge accumulated: The researchers confirmed most of the design knowledge that they had accumulated for the Business Model Canvas (Figure 7). The main differences were that, in this case, framing a problem did not require the development of an ontology; a conceptual framework was sufficient. However, the conceptual framework included not only aspects that could be designed by users (i.e., pain relievers, gain creators, and products and services), but also aspects that could only be observed, such as the jobs to be done, and the gains and pains that characterize a certain customer profile. This differed from the Business Model Ontology, which contained only elements that could be designed by the organizations (DK1.2 in Figure 7). Overall, the design of the conceptual framework of the Value Proposition Canvas confirmed that the problem needed to be framed and defined with academic knowledge that covered all its main constituents with precise definitions, while the number of constituents needed to remain parsimonious. 
Table 4. Summary of the DSR Project for the Value Proposition Canvas

\begin{tabular}{|c|c|c|c|}
\hline Cycle & $\begin{array}{l}\text { 1: Defining the management } \\
\text { concept }\end{array}$ & $\begin{array}{l}\text { 2: Translating the management } \\
\text { concept into a tool for joint } \\
\text { inquiry }\end{array}$ & $\begin{array}{l}\text { 3: Stabilizing directions for } \\
\text { joint inquiry }\end{array}$ \\
\hline Period & 2011 to 2012 & 2012 to 2013 & 2013 to 2014 \\
\hline Problem domain & $\begin{array}{l}\text { Users of the Business Model Canvas } \\
\text { focused on the Value Proposition } \\
\text { building block whenever their offer } \\
\text { was not clear. Space was limited and } \\
\text { there was guidance for designing } \\
\text { value propositions. }\end{array}$ & $\begin{array}{l}\text { The researchers needed to find a } \\
\text { shared visualization for the } \\
\text { conceptual model. }\end{array}$ & $\begin{array}{l}\text { The researchers needed to } \\
\text { define the directions for use } \\
\text { that would allow } \\
\text { practitioners to inquire into } \\
\text { different solutions. }\end{array}$ \\
\hline $\begin{array}{l}\text { Design } \\
\text { requirement }\end{array}$ & How to define a value proposition? & $\begin{array}{l}\text { How does one represent the } \\
\text { conceptual framework visually? }\end{array}$ & $\begin{array}{l}\text { How does one use the Value } \\
\text { Proposition Canvas } \\
\text { effectively? }\end{array}$ \\
\hline $\begin{array}{l}\text { Solution domain } \\
\text { (artifacts) }\end{array}$ & $\begin{array}{l}\text { - Value Proposition conceptual } \\
\text { model }\end{array}$ & - Value Proposition Canvas & $\begin{array}{l}\text { - Value Proposition Design } \\
\text { (book) }\end{array}$ \\
\hline $\begin{array}{l}\text { Joint inquiry } \\
\text { techniques } \\
\text { (Steen, 2013) }\end{array}$ & - Defining & $\begin{array}{l}\text { - Ideating } \\
\text { - Prototyping }\end{array}$ & $\begin{array}{l}\text { - Ideating } \\
\text { - Prototyping }\end{array}$ \\
\hline
\end{tabular}

\subsubsection{Cycle 2: Translating the Management Concept into a Tool for Joint Inquiry}

Problem domain: The second activity translated the conceptual model into a shared visualization by reusing the same format as used in the Business Model Canvas, i.e., a shared printed poster. However, as stated above, the main issue was to identify the best visual representation for the building blocks, as some pertained to the value proposition as such, while others to the customer profile. In addition, a design question arose because some components of the conceptual framework can be designed by the practitioners (i.e., products or services, gain creators, and pain relievers), while others can only be observed and used as decisional information (i.e., the jobs to be done, gains and pains, etc.). In these cycles, the researchers sought to answer the question: How can this conceptual framework be visually represented?

Solution domain. After trying out various prototypes for the visual representation, the researchers collaborated with a visual designer to develop the current version (Figure 2). The layout of this version was finalized after evaluations with 55 undergraduate students and feedback from 60 practitioners who had been extensive users of the Business Model Canvas.

The Value Proposition Canvas has two sides: the customer profile on the right (or, customer segment in the Business Model Canvas), and the value proposition on the left, which describes the products or services that the organizations offer or can offer for the job identified in the customer profile. The Value Proposition Canvas seeks a balance between the two parts that creates a value proposition that is in line with customer expectations. The rationale for having both building blocks in the same tool derives from the holistic approach that the researchers used for the
Business Model Canvas, i.e., that all parts (building blocks) of business models should be considered as parts of a coherent whole.

Design knowledge accumulated: The designers reused most of the design knowledge and intuitions they had for the Business Model Canvas: create a shared visualization that allows users to ideate and prototype solutions, place the building blocks in the Business Model Canvas according to their relationships, and use visual metaphors to facilitate an understanding of the components.

However, the researchers made a different design decision from that of the Business Model Canvas in that they differentiated visually between what the users could design solutions for and what could only be used as decision-making information. Thus, the value proposition block was displayed as a square - to reflect the value proposition in the Business Model Canvaswhile the customer profile was represented as a circle. This accentuated the difference between filling in the customer profile with information and filling in the value proposition with potential solutions.

\subsubsection{Cycle 3: Stabilizing Directions for Joint Inquiry}

Problem domain: The last cycle of the development was dedicated to evaluating whether the same directions for use of the Business Model Canvas could be applied to the Value Proposition Canvas. Therefore, the question that motivated this cycle was: How can the Value Proposition Canvas be used effectively?

Solution domain: The researchers used the same rationale for the directions for use. They suggested the use of sticky notes for the visualization, flexibility, and conciseness they provide. The Value Proposition Canvas was also used during workshops or team 
meetings for guided ideation. All the directions for use were formalized and illustrated in Osterwalder et al. (2014). The use of the Value Proposition Canvas differs from the Business Model Canvas in several ways. First, the directions for use stipulate that users should start on the right, i.e., the customer profile identified in the Business Model Canvas. Second, color-coding is not as important as it is for the Business Model Canvas, as the focus is preferably on one single customer profile, rather than the search for multiple solutions as is the case in the Business Model Canvas, because the Value Proposition Canvas serves as a plugin to the Business Model Canvas that dives deeper into the value propositions and customer profiles identified in the business model. If users want to generate alternative solutions for alternative customer profiles, it is recommended that they use multiple canvases. Finally, the directions for use emphasize the need to be as exhaustive as possible, concerning the number of elements that users employ for each building block, in order to enhance ideation.

Design knowledge accumulated: This design cycle and its evaluation confirmed several design decisions. First, framing and defining the directions for use, as in the Business Model Canvas, proved effective to practitioners because it allowed them to use the ideation and prototypical design thinking techniques with a visual representation that frames the content toward which these activities need to be directed. The use of questions to frame the ideation and prototyping activities was also retained for the Value Proposition Canvas, which includes questions for each building block. Second, the use of sticky notes provides tangible, flexible, and concise marks that allow practitioners to easily add, amend, or remove elements when ideating and prototyping solutions to the value proposition. The sticky notes also proved useful for presenting solutions to other stakeholders in a storytelling manner.

Some design knowledge that the researchers acquired during the development was not reflected in the Business Model Canvas. On the one hand, prototyping was more efficient if done through multiple instantiations of the Value Proposition Canvas, rather than through color-coding to differentiate between the solutions. On the other hand, the Value Proposition Canvas confirmed the designers' intuitions that different visual inquiry tools could be used separately in an integrated fashion. In essence, the Value Proposition Canvas zooms into two building blocks of the Business Model Canvas, allowing users to focus on a subset of the elements of business modeling.

\subsubsection{Summary of the Design Knowledge Accumulation and Evolution}

An overview of the design knowledge accumulated throughout the entire project is provided in Figure 8. Overall, the development of the Value Proposition Canvas confirmed the need to frame the management problem of interest. While this was done with an ontology for the business model, a conceptual framework proved sufficient for the value proposition. Second, the need to represent the conceptual model into a shared visualization to make it more accessible and appropriate for design thinking was confirmed.

\begin{tabular}{|c|c|c|}
\hline Cycle 1 & Cycle 2 & Cycle 3 \\
\hline $\begin{array}{l}\text { DK1.1: The conceptual model helped structure } \\
\text { the definition of the value proposition }\end{array}$ & $\begin{array}{l}\text { DK2.1: Representing the conceptual model into a } \\
\text { shared design space allows practitioners to co- } \\
\text { design value propositions }\end{array}$ & $\begin{array}{l}\text { DK3.1: The Canvas and its use are valid, useful, } \\
\text { usable, effective, intelligible, and satisfactory }\end{array}$ \\
\hline $\begin{array}{l}\text { DK1.2: Using the jobs-to-be done theory helped } \\
\text { users formulate and define value propositions }\end{array}$ & $\begin{array}{l}\text { DK2.2: The design spaces of the tool supported } \\
\text { the ideation and prototyping of solutions }\end{array}$ & $\begin{array}{l}\text { DK3.2: The mechanics of the tool outlined the } \\
\text { best practices for using the canvas for ideation } \\
\text { and prototyping }\end{array}$ \\
\hline $\begin{array}{l}\text { DK1.3: The domains (building blocks) covered all } \\
\text { aspects of value proposition design and were } \\
\text { each clearly defined }\end{array}$ & $\begin{array}{l}\text { DK 2.3: Design thinking techniques should be } \\
\text { developed for users not to conceive of the } \\
\text { building blocks as separate checklists }\end{array}$ & $\begin{array}{l}\text { DK3.3: Directions for testing and evaluating } \\
\text { hypotheses should be included }\end{array}$ \\
\hline $\begin{array}{l}\text { DK1.4: The development was based on } \\
\text { academic knowledge }\end{array}$ & $\begin{array}{l}\text { DK 2.4: The visual metaphors and logos } \\
\text { facilitated the understanding of the Canvas }\end{array}$ & $\begin{array}{l}\text { DK3.4: Computer-aided design capabilities are } \\
\text { better suited for testing and evaluating than } \\
\text { paper-based Canvas }\end{array}$ \\
\hline $\begin{array}{l}\text { DK 1.5: The conceptual model included a } \\
\text { parsimonious number of elements and questions }\end{array}$ & $\begin{array}{l}\text { DK 2.5: The physical proximity of the interrelated } \\
\text { building blocks facilitated the presentation of } \\
\text { solutions with a fit between the two sides }\end{array}$ & $\begin{array}{l}\text { DK } 3.5 \text { Using post-it notes provides tangible } \\
\text { marks which facilitate the presentation of } \\
\text { solutions to other stakeholders }\end{array}$ \\
\hline & $\begin{array}{l}\text { DK 2.6: The parsimonious number of elements } \\
\text { and questions facilitated the use of the tool }\end{array}$ & \\
\hline
\end{tabular}

Figure 8. Design Knowledge Accumulation for the Value Proposition Canvas 
However, the Value Proposition Canvas suggests that building blocks could also be used for informational purposes only, as is the case with the customer profile segment. Third, the project confirmed the need to define directions for use, which were articulated through questions related to each building block in the tool and in the Value Proposition Design book (see Osterwalder, Pigneur, Bernarda \& Smith, 2014). The researchers were also influenced by the lean startup approach and developed testing cards that could be used along with the Value Proposition Canvas. The cards allow users to test the hypotheses of the solutions to the value proposition they design and evaluate their potential fit with a specific customer segment. Finally, this project provided some additional design knowledge that the designers did not have when developing the Business Model Canvas. The development of the Value Proposition Canvas suggests that visual inquiry tools can be integrated and combined to address different management problems.

\subsubsection{First Episode of Theorizing and Communicating the Design Knowledge}

Equipped with the design knowledge they acquired from the two projects, the designers sought to communicate and share it with practitioners who were experts in specific management problems. The designers had the intuition that any management concept or problem could be translated into a visual tool. Therefore, they shared their knowledge and guided practitioners in the design of a visual inquiry tool for their own strategic problems. These were tested during a two-day workshop in 2013 called the Business Design Summit, which was attended by 280 practitioners.

The workshop was structured as follows. The designers of the Business Model Canvas shared their expertise and the design knowledge they had gathered with 14 scholars before the summit. These scholars designed an artifact related to their domain of expertise and presented their artifacts to the workshop participants and guided them through hands-on activities intended to help them use these newly designed tools.

The design knowledge that the designers shared included the contextual background of the two DSR projects and the development process of the two visual inquiry tools. Their design knowledge was not formalized into a development process or principles of form and function that developers could follow. Rather, they primarily related the overall main elements, i.e., the need to define the management problem and instantiate it into a shared visualization.

While none of the participants managed to develop a visual inquiry tool during the two days of the workshop, some developers continued development after the workshop. One of the most notable examples is Dave
Gray's Culture Map for managing change initiatives (Gray, 2015). Overall, the Business Design Summit highlighted the interest of practitioners from a variety of domains in the development of visual tools that support design thinking techniques for specific management problems. The experience also indicated that the design knowledge needed to be formalized in a clear and practical way that developers of additional visual inquiry tools could build upon.

\subsubsection{The Team Alignment Map: An Independent Development of a Visual Inquiry Tool}

Hereafter, we present another case that was developed independently from the previous two. Overall, the Team Alignment Map had three main cycles; each addressed a different kind of problem and research questions relating to team alignment and coordination (Table 5). One major difference from the other two projects is the order of development for Cycles 2 and 3. Instead of first designing the visual inquiry tool and later developing artifacts for evaluation, the designers of the Team Alignment Map proceeded in reverse. In the following subsections, we relate the problem and solution domains of the three development cycles and outline the design knowledge common to and different from the previous two projects.

\subsubsection{Cycle 1: Defining the Management Concept}

Problem domain: The first cycle also concerned the practitioners' understanding of the problem i.e., How can project team members coordinate their contributions when undertaking uncertain, complex, and innovative projects? While coordination has been the subject of extensive research, most studies on team coordination and project management methodologies have failed to provide concrete guidance on the process that should be followed to coordinate effectively. Most of the perspectives on team coordination have either treated it as a black box (Cannon-Bowers \& Salas, 2001) or only attended to it via organizational design (e.g., Malone \& Crowston, 1994). Project management methodologies often explicitly state that team coordination is a critical factor but do not provide any actionable knowledge on how to ensure it. The DSR project thus started with the question: How can team coordination in projects be defined?

Solution domain: Given the emphasis on discussion and conversation, the designers turned to the work of Clark (1996) who provides a theory of human coordination through discussion. Clark's work is inscribed in psycholinguistics and focuses on cases in which two individuals coordinate to complete simple tasks. 
Table 5. Summary of the DSR project for the Team Alignment Map

\begin{tabular}{|l|l|l|l|}
\hline Cycle & $\begin{array}{l}\text { 1: Defining the management } \\
\text { concept }\end{array}$ & $\begin{array}{l}\text { 2: Developing methods for } \\
\text { evaluation }\end{array}$ & $\begin{array}{l}\text { 3: Translating the management } \\
\text { concept into a tool for joint } \\
\text { inquiry and stabilizing directions } \\
\text { for use }\end{array}$ \\
\hline Period & $2010-2014$ & $2014-2015$ & $2015-2017$ \\
\hline $\begin{array}{l}\text { Problem } \\
\text { domain }\end{array}$ & $\begin{array}{l}\text { Need to define what team } \\
\text { members should discuss during } \\
\text { project meetings to coordinate } \\
\text { effectively. }\end{array}$ & $\begin{array}{l}\text { Practitioners required a way to } \\
\text { evaluate the potential for } \\
\text { coordination (alignment on the } \\
\text { four requirements) in real-time } \\
\text { during meetings. }\end{array}$ & $\begin{array}{l}\text { Practitioners required a way to } \\
\text { codesign the content of the four } \\
\text { requirements during team meetings. }\end{array}$ \\
\hline $\begin{array}{l}\text { Design } \\
\text { requirement }\end{array}$ & $\begin{array}{l}\text { How to define team } \\
\text { coordination in projects? }\end{array}$ & $\begin{array}{l}\text { How to evaluate the potential for } \\
\text { coordination in a project team? }\end{array}$ & $\begin{array}{l}\text { How can team members codesign } \\
\text { their project coordination? }\end{array}$ \\
\hline $\begin{array}{l}\text { Solution } \\
\text { domain }\end{array}$ & $\begin{array}{l}\text { - COOPilot conceptual model } \\
\text { - COOPilot Cards }\end{array}$ & $\begin{array}{l}\text { - COOPilot App v1 } \\
\text { - COOPilot App v2 }\end{array}$ & $\begin{array}{l}\text { - Team Alignment Map } \\
\text { - Directions for use }\end{array}$ \\
\hline $\begin{array}{l}\text { Joint inquiry } \\
\text { techniques } \\
\text { (Steen 2013) }\end{array}$ & $\bullet$ Defining & - Testing & $\begin{array}{l}\text { Ideating } \\
\text { - Prototyping }\end{array}$ \\
\hline
\end{tabular}

The researchers adapted Clark's theory for cases in which there are multiple individuals and the joint activities are complex and continue over a long time span; e.g., IS projects. They developed the COOPilot conceptual model, which translated Clark's fundamental requirements for coordination to project management (Mastrogiacomo et al., 2014). The conceptual model outlines the four requirements that teams must discuss during project meetings to coordinate effectively. The designers instantiated the conceptual model into a set of cards, i.e., the COOPilot Cards (Figure A5). The cards were used by project managers as visual support used to estimate the level of common ground among all team members during project meetings so that they could adjust discussions according to the domains that required further explanation and agreement.

Design knowledge accumulated: The evaluations of this design cycle showed that frequent and recurrent use of the COOPilot Cards augmented the level of common ground and thus reduced the number of coordination breakdowns (Mastrogiacomo et al., 2014). The evaluation confirmed the usefulness and validity of the conceptual model to frame team coordination during team meetings. This highlighted the relevance of adapting Clark's theory to project teams and the need to frame the problem of interest with a conceptual framework. The evaluation also covered each of the four domains of the conceptual model and concluded that they were all clearly defined and useful. The users also highlighted the relative simplicity of the conceptual model.

\subsubsection{Cycle 2: Developing Methods for Evaluation}

Problem domain: Following the promising results of the first study on the COOPilot conceptual model and cards, the researchers decided to extend and refine the mobilization of the concept of common ground in project management. The researchers focused their efforts on improving the way that the level of common ground was assessed during project meetings. This decision was motivated by theoretical considerations and feedback from practitioners.

On the practical side, during the workshops with practitioners that the researchers conducted using the COOPilot conceptual model and cards, participants emphasized their interest in having an artifact that would allow them to explicitly ask every project team member about their understanding of the four requirements, rather than leaving it to the project manager's perception. On the theoretical side, the researchers sought to find a more accurate way to quantify the level of common ground and, consequently, assess the relevance of the concept of common ground in project management with more precise analyses. In fact, the evaluation of the level of common ground with the COOPilot cards was based on perceptions of perceptions (i.e., project managers' perceptions of their peers' perceptions about the project), thus adding considerable bias. Therefore, the researchers developed a second DSR cycle in which they tried to answer the question: How can the level of common ground reflecting the potential for coordination of project teams be measured?

Solution domain: This question motivated the instantiation of the COOPilot conceptual model into a mobile application, the COOPilot App (Figure A6). The level of common ground (and, thus, the potential for coordination) was represented by vote scattering: the more votes on the right side of the continuum, the more common ground and potential for coordination team members had. The developers added a numerical result that computed the potential for coordination in a percentage. This version of the model also included a 
conversational guide containing questions for each requirement that the team could use to trigger a repair discussion in case their level of common ground was too low.

Design knowledge accumulated: The evaluation of this design cycle outlined three major findings. First, the app provided effective assessments of the level of common ground, which were more accurate than those acquired using the paper-based COOPilot cards. Second, the COOPilot App triggered two types of corrective actions that could be implemented when the level of common ground was low. In some cases, project teams started collective discussions on the domains that required further explanation. In others, when the level of common ground was too low, project teams decided to end the project because it was deemed too costly or political to address the misunderstandings. Finally, the evaluations underlined the importance of making use of the dynamic guiding capabilities that digital artifacts can support. This version of the model included a set of questions to trigger remedial conversations, which were followed when the level of common ground was low. This feature provided users not only with an evaluation of their potential for coordination but also with the strategies to implement in response to the evaluation.

\subsubsection{Cycle 3: Translating the Management Concept into a Joint Inquiry Tool and Stabilizing Directions for Use}

Problem domain: The evaluation in the second cycle suggested that the COOPilot Cards and the COOPilot App did not provide all the supportive guidance that project teams needed for coordinating. The problem that was addressed in this cycle relates to the need for several project team members to define the content of the four domains collectively with their peers during team meetings. In the first two cycles, practitioners were only provided with the means to understand the requirements for coordination (COOPilot Cards) and evaluate their team's position regarding these requirements (COOPilot App). Feedback from practitioners outlined the need for the development of a visual inquiry tool for team coordination. This led the researchers to question: How can team members codesign their project coordination?

Solution domain: To answer this question, the researchers designed the Team Alignment Map. Similar to the previous two projects, the researchers' intuition was that teams needed a shared design space that they filled in together during team meetings. Thus, the researchers displayed the four requirements as four empty design spaces next to each other on a shared and printed canvas-like visual. The order of the design spaces reflected Clark's (1996) implicit relationships between the four requirements. For any joint activity, individuals must first identify the joint objectives, after which they define what part they can commit to and, finally, assess whether they have the ability to do their part (joint resources and no joint risks). The researchers also used the same icons used in the COOPilot Cards and COOPilot App to create consistency across all formats and provide users visual cues to understand the four requirements more easily.

The researchers defined directions for use to make the most out of the tool. These directions evolved over time as feedback from the observation and evaluation of the tool in use was gathered. One stable functional support comprised the set of questions for each requirement stimulated collective discussions and ideation among project teams. The researchers felt that questions were the best way to trigger collective ideation, just as the designers of the Business Model Canvas and the Value Proposition Canvas did. For instance, to design the joint objectives, users should ask themselves what they intend to do together.

In addition, the researchers developed and refined directions for ideating the content of the four requirements and prototyping solutions. They first suggested that users fill the four design spaces from left to right (which they called the forward pass). They noticed that users conceived of the four design spaces as separate checklists providing the elements that they should think about and discuss. Therefore, the researchers stressed some rules that should be followed to ensure a coherent and exhaustive solution, such as making sure that there was at least one person committed to each objective.

Design knowledge accumulated: The evaluation of the Team Alignment Map (Avdiji et al., 2018) confirmed that the function of the tool facilitated quick ideation and prototyping of different solutions and arrangements regarding the four requirements and improved and changed the way that project meetings were conducted. The tool was also deemed easy to understand and use because of the parsimonious number of elements in the tool, the visual support provided by icons, and the fact that some members were familiar with the Business Model Canvas and the logic of using sticky notes for ideation.

The evaluation also led to one major amendment of the tool. Initially, the researchers integrated scales for team members to display their understanding of each domain using the same logic as the sliding features in the mobile app. However, this function was never used and teams resorted to using the COOPilot App whenever they wanted to evaluate their level of common ground. The evaluation suggested that it was more effective to separate the two functions of the tools, as they activated different discussions and ways of thinking with which the teams were not comfortable. 


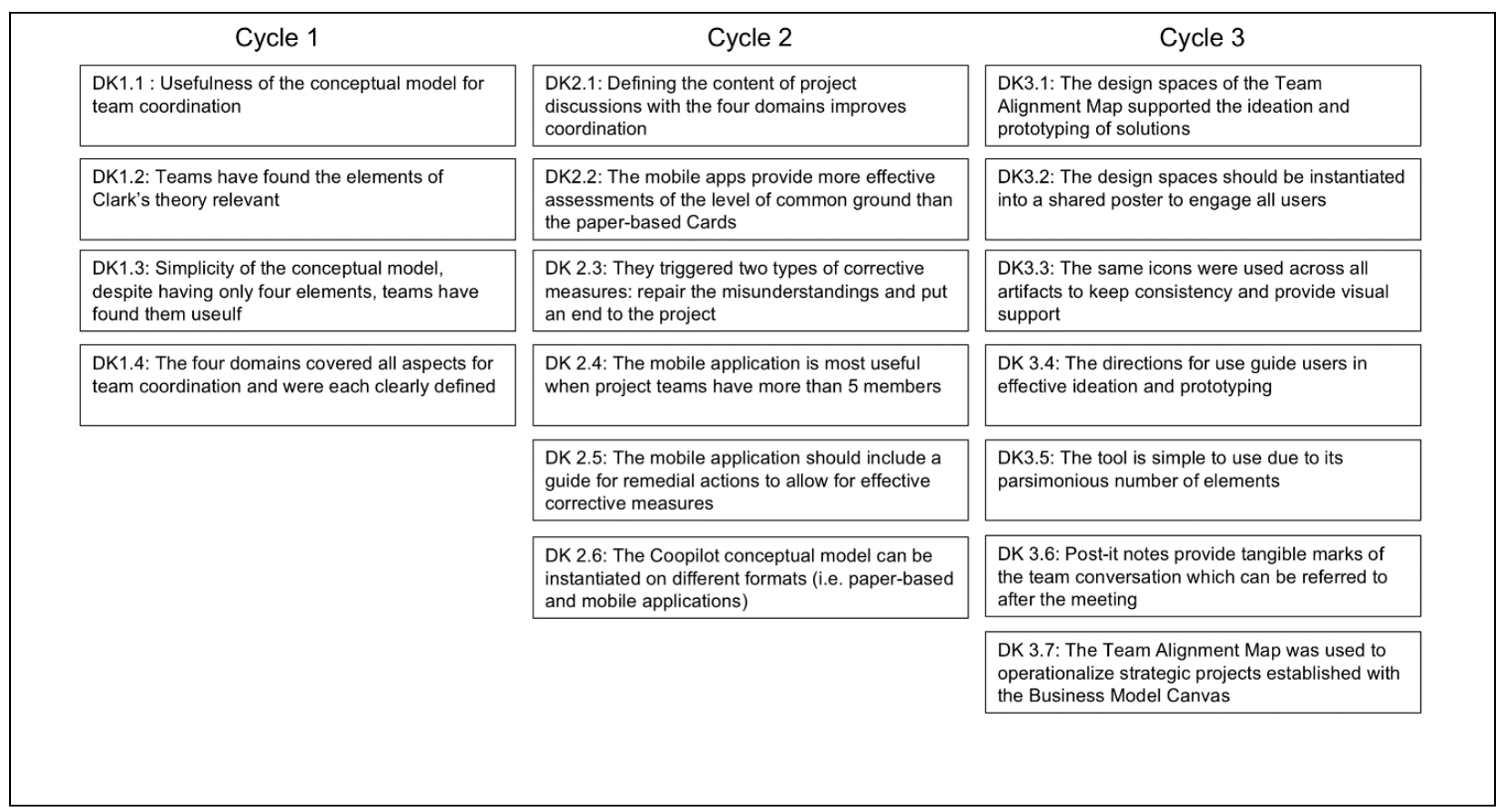

Figure 9. Design Knowledge Accumulation for the Team Alignment Map

\subsubsection{Summary of the Design Knowledge Accumulation and Evolution}

An overview of the design knowledge accumulated throughout the entire project is provided in Figure 9. Overall, the development of the Team Alignment Map highlights a finding that is similar to the previous two projects: the importance of developing a conceptual model that outlines the elements into which team members must jointly inquire in order to coordinate effectively. The importance and value of developing a visual inquiry tool for team coordination were confirmed in different settings. Similarly, the mobile application covers the need to evaluate solutions, while the visual inquiry tool supports the ideation and prototyping of solutions. The major differences lie in the way these requirements were met through the specific design features.

\subsection{The Design Theory for Visual Inquiry Tools}

The in-depth analysis of the development process of each case allowed us to identify the different problems, solutions, and design knowledge that the researchers activated throughout the project. Our design theory provides prescriptive knowledge for developing what we term visual inquiry tools, i.e., visual tools that guide teams of practitioners to develop hypotheses and potential solutions to specific strategic management problems. In other words, the purpose of the design theory is to support researchers and practitioners in developing such tools. In that sense, our design theory is the second episode of the formalization and communication of design knowledge, the first being the Design Summit. The major difference is in the way that design knowledge is formalized-here, using Gregor and Jones's (2007) framework - and the DSR projects from which it evolved. A summary of the design theory is provided in Table 6. In the following subsection, we explain the design principles and the mutability in greater detail.

\subsubsection{Design Principle 1: Conceptual Model}

The first step toward the development of the tool is the creation of a conceptual model that frames and articulates a management concept of interest.

DP1.1. Frame: The first subprinciple that designers should carefully attend to is the development of a conceptual model that appropriately frames the business concept. The frame is critical as it sets the scope and purpose for the joint inquiry and thereby influences how practitioners will address the business concept. Thus, designers should have a clear and explicit understanding of their paradigm or foundational assumptions about the problem. All three projects address the business concept through a specific lens. For example, the Business Model Canvas examines the business model from an internal perspective, whereas the Team Alignment Map, addresses team alignment from a conversation perspective. Further, the building blocks of the conceptual model should simultaneously be mutually exclusive and collectively exhaustive. All the building blocks should be clearly scoped and defined so that there are no characteristics and attributes that overlap with other building blocks. Designers should also ensure that the building blocks cover all of a problem's relevant aspects. 
Table 6. Components of the Design Theory for Visual Inquiry Tools

Based on Gregor \& Jones's (2007) Framework.

\begin{tabular}{|c|c|c|}
\hline Component & Description & Application \\
\hline $\begin{array}{l}\text { 1. Purpose } \\
\text { and scope }\end{array}$ & $\begin{array}{l}\text { "What the system is for": the } \\
\text { set of metarequirements or } \\
\text { goals that specify the type of } \\
\text { artifact to which the theory } \\
\text { applies and, in conjunction, } \\
\text { also define the scope, or } \\
\text { boundaries, of the theory }\end{array}$ & $\begin{array}{l}\text { This design theory is intended for designers who wish to develop visual } \\
\text { inquiry tools. The purpose of these tools is to guide cross-boundary teams } \\
\text { of practitioners in jointly inquiring into specific strategic management } \\
\text { problems. Joint inquiry is the process through which individuals (1) } \\
\text { articulate and explore the strategic management problem, and (2) develop } \\
\text { and evaluate alternative hypotheses about how to solve the problem. Such } \\
\text { problems are typically solved by cross-boundary teams, i.e., those teams } \\
\text { with knowledge boundaries (Carlile, 2004; Edmondson \& Harvey, 2017). }\end{array}$ \\
\hline 2. Constructs & $\begin{array}{l}\text { Representations of the entities } \\
\text { of interest in the theory }\end{array}$ & $\begin{array}{l}\text { Strategic management problems, joint inquiry, conceptual model, shared } \\
\text { visualization, inquiry techniques, cross-boundary teams. }\end{array}$ \\
\hline $\begin{array}{l}\text { 3. Principles } \\
\text { of form and } \\
\text { function }\end{array}$ & $\begin{array}{l}\text { The abstract "blueprint" or } \\
\text { architecture that describes an } \\
\text { IS artifact, either product or } \\
\text { method/intervention }\end{array}$ & 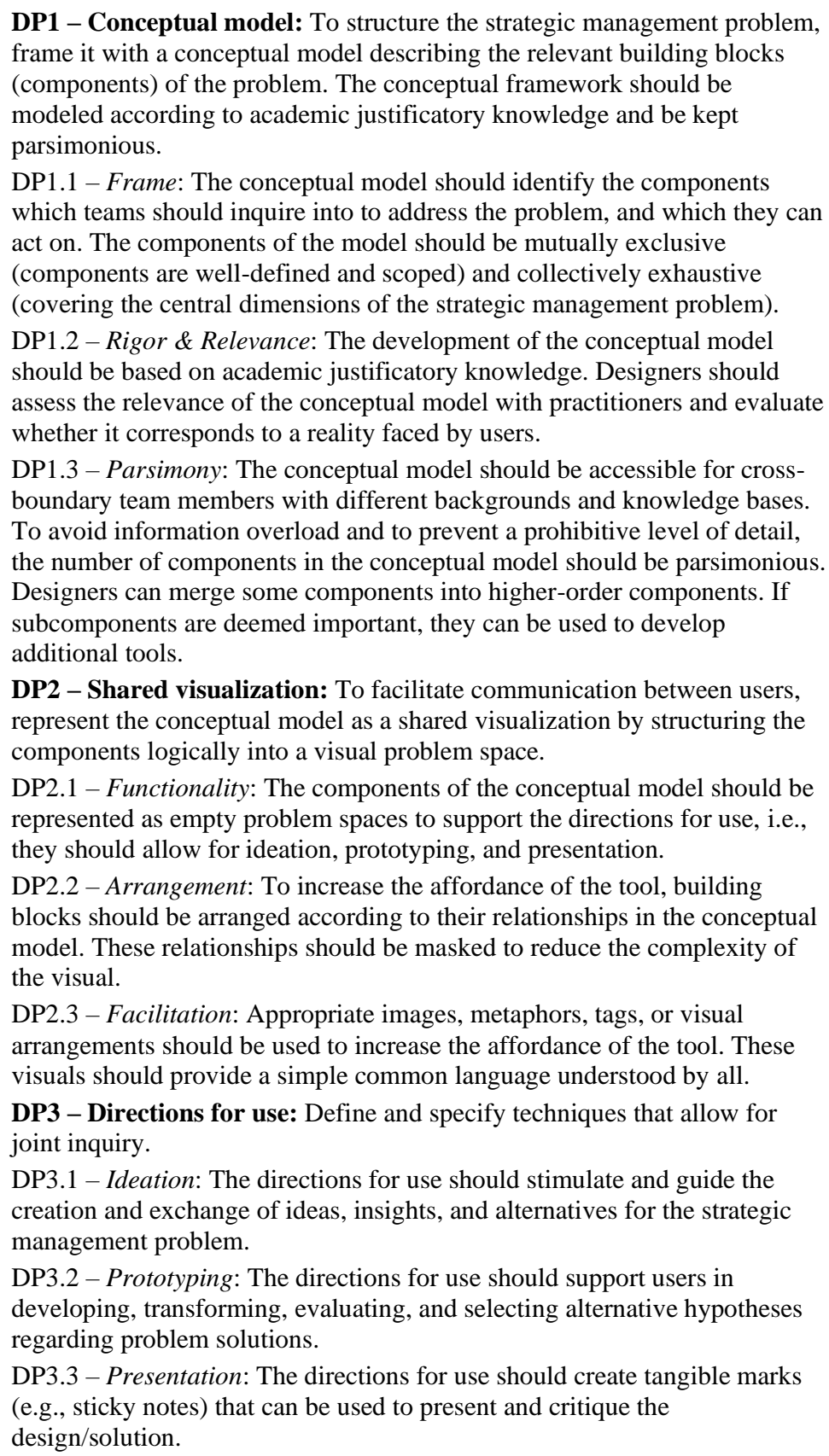 \\
\hline
\end{tabular}


Table 6. Components of the Design Theory for Visual Inquiry Tools (cont.)

\begin{tabular}{|c|c|c|}
\hline $\begin{array}{l}\text { 4. Artifact } \\
\text { mutability }\end{array}$ & $\begin{array}{l}\text { The changes in the state of the } \\
\text { artifact anticipated in the } \\
\text { theory-that is, what degree of } \\
\text { artifact change is encompassed } \\
\text { by the theory }\end{array}$ & $\begin{array}{l}\text { Flexibility of use: Due to the flexible nature of visual inquiry tools, } \\
\text { use cases that differ from the directions for use can be anticipated. } \\
\text { These can even change the nature of the artifact. For instance, the } \\
\text { building blocks might also be used to set numerical objectives rather } \\
\text { than using sticky notes for ideation and prototyping. } \\
\text { Flexibility of evolution: The conceptual frameworks can be } \\
\text { represented visually in different ways and on different media. For } \\
\text { instance, it can be represented on a paper-based shared poster or it can } \\
\text { be instantiated into a CAD. } \\
\text { Flexibility of integration: The visual inquiry tools may not and cannot } \\
\text { cover all the aspects of the strategic management problem. Integrations } \\
\text { or synergies between the visual inquiry tools and tools that cover } \\
\text { additional aspects of the specific problems can be anticipated. }\end{array}$ \\
\hline $\begin{array}{l}\text { 5. Testable } \\
\text { propositions }\end{array}$ & $\begin{array}{l}\text { Truth statements about the } \\
\text { design theory }\end{array}$ & $\begin{array}{l}\text { The visual inquiry tools that implement the aforementioned principles } \\
\text { can be tested by following Checkland (2000). Hereafter, we list the } \\
\text { criteria that are suggested to be used in the evaluation of the visual } \\
\text { inquiry tools: } \\
\text { TP1 - Efficacy: The use of the visual inquiry tool supports and } \\
\text { improves the outcomes of a process of joint inquiry into a strategic } \\
\text { management problem. } \\
\text { TP2 - Effectiveness: The visual inquiry tool can be successfully used } \\
\text { by individuals and groups within the context of the particular } \\
\text { managerial problem and organizational context for which it was } \\
\text { designed. } \\
\text { TP3 - Efficiency: The use of the visual inquiry tool does not require } \\
\text { an inappropriate amount of time or other resources. } \\
\text { TP4 - Elegance (Aesthetics): The shared visualization in the tool is } \\
\text { easy to understand and use. } \\
\text { TP5 - Ethicality: Participants in the inquiry using the tool are not } \\
\text { disadvantaged by the outcomes of the joint inquiry compared to other } \\
\text { participants, nor are they injured or stressed in the joint inquiry } \\
\text { process. }\end{array}$ \\
\hline $\begin{array}{l}\text { 6. Justificatory } \\
\text { knowledge }\end{array}$ & $\begin{array}{l}\text { The underlying knowledge or } \\
\text { theory from the natural or social } \\
\text { or design sciences that gives a } \\
\text { basis and explanation for the } \\
\text { design (kernel theories) }\end{array}$ & $\begin{array}{l}\text { Our design theory is supported by theoretical developments in } \\
\text { ontology development, shared visualization, joint inquiry, and strategic } \\
\text { problems in management. The design theory is also supported by the } \\
\text { knowledge accumulated through the three DSR cases and their related } \\
\text { physical instantiations. }\end{array}$ \\
\hline $\begin{array}{l}\text { 7. Principles of } \\
\text { implementation }\end{array}$ & $\begin{array}{l}\text { A description of processes for } \\
\text { implementing the theory (either } \\
\text { product or method) in specific } \\
\text { contexts }\end{array}$ & $\begin{array}{l}\text { The process of implementation of this theory is highly iterative. All the } \\
\text { principles are interrelated and interdependent. Each of the three } \\
\text { principles should be applied in iterative phases of design and testing. } \\
\text { First, the designers should develop a conceptual framework, evaluate } \\
\text { it, and refine it until they reach a point of stabilization. Then they } \\
\text { should instantiate it into a shared visualization that needs to be tested } \\
\text { and refined. This instantiation might indicate some inconsistencies in } \\
\text { the conceptual model, which might require a refinement of the } \\
\text { conceptual framework. When the visual instantiation reaches a point of } \\
\text { closure, designers can consider specifying the directions for use of } \\
\text { their tool. Because the directions for use are highly dependent on the } \\
\text { visualization, designers may have to refine the visual before reaching a } \\
\text { point of stabilization. }\end{array}$ \\
\hline $\begin{array}{l}\text { 8. Expository } \\
\text { instantiations }\end{array}$ & $\begin{array}{l}\text { A physical implementation of } \\
\text { the artifact that can assist in } \\
\text { representing the theory as an } \\
\text { expository device and for } \\
\text { purposes of testing }\end{array}$ & $\begin{array}{l}\text { The Business Model Canvas } \\
\text { The Value Proposition Canvas } \\
\text { The Team Alignment Map }\end{array}$ \\
\hline
\end{tabular}


DP1.2. Rigor and relevance: The conceptual model should provide a rigorous and relevant account of a business concept. The development of the conceptual model should be based on academic justificatory knowledge in order to establish validity and accuracy and different strategies for the development of the conceptual model can be used. However, the model should also be relevant in that it accurately represents the reality faced by practitioners. In all three projects, relevance was ensured by extensively testing and refining it in real contexts.

DP1.3. Parsimony: Finally, the conceptual model should be simple, so that it is easily understood by the heterogeneous members of cross-boundary teams, and should avoid a prohibitive level of detail that would undermine its affordance. Thus, the number of building blocks should be parsimonious; the three projects discussed here use between four and nine building blocks.

\subsubsection{Design Principle 2: Shared visualization}

The second design principle regards the instantiation of the conceptual model into a shared visualization using various techniques. Designers should follow the three subprinciples that were informed by the three projects in order to develop an effective shared visualization. They can also call upon experienced graphic designers, as the designers did in all three projects.

DP2.1. Functionality: The shared visualization should support the tool's intended functions. Thus, they should be aligned with the directions for use (DP3) and allow for exploration, hypothesis generation, and presentation. In all three projects, this was achieved by representing the conceptual model's components as empty design spaces or building blocks. Practitioners generate hypotheses by using tangible marks in the form of sticky notes that are added to the building blocks. This allows team members to represent their opinions and assumptions on a strategic management problem.

DP2.2. Arrangement: To facilitate the affordance of the tool, the associations between the building blocks should be masked but implied in the way they are visually arranged. The Team Alignment Map organizes the building blocks from left to right, following the conventional Western reading direction, to suggest that users should inquire into joint objectives first and should then move on to the joint commitments, and so on. Their arrangement reflects the processual associations between the building blocks. If the associations are important for the users to explicitly understand, designers can incorporate them either in the directions for use or through illustrative use cases, as is the case for the Business
Model Canvas. The building blocks of the Value Proposition Canvas were arranged according to their relationships, as reflected in the Business Model Canvas.

DP2.3. Facilitation: Finally, designers can make use of various aesthetics to facilitate the affordance of the tool and provide a shared language that is understood by all users. The designers of all three projects used techniques such as appropriate metaphors, icons, written explanations, and shapes. For instance, every building block of the Business Model Canvas is named and has a corresponding metaphor in the form of an icon. The value proposition is depicted as a gift, suggesting that it is what the company should offer its customers. The Team Alignment Map's designers also used an arrow and a darker shade for missing resources and joint risks, suggesting that users should seek to transfer these into objectives or commitments to the greatest extent possible. Thus, risks and missing resources represent obstacles that can be overcome if someone does something to mitigate them, hence their translation into objectives and commitments.

\subsubsection{Design Principle 3: Directions for Use}

The last design principle relates to the need for designers to define and specify directions for use that guide the joint inquiry process. Designers should conceive a visual inquiry tool in a way that facilitates (1) the exploration of a problem space, (2) the generation of hypotheses on the solutions to a problem, and (3) the presentation and critical review of the solution.

DP3.1. Ideation: The directions for use should be defined in a way that stimulates the creation and exchange of ideas and insights between team members. A key characteristic of strategy is that there is no single best solution, so practitioners must be supported in their ideation and creativity processes. All three tools promote a collaborative use in cross-boundary teams and allow individuals to tap into their diverse set of knowledge, expertise, and resources to generate and share creative ideas (Edmondson \& Harvey, 2017; Katzenbach \& Smith, 2015). For instance, the use of sticky notes facilitates the process of generating ideas, as they force individuals to generate small chunks of information that can be combined and recombined to come up with an extensive number of possibilities (Sibbet, 2011).

DP3.2. Prototyping: The directions for use should also guide the generation, transformation, evaluation, and selection of hypotheses regarding how to solve a management concept strategically. The use of sticky notes facilitates this process since users can easily and flexibly fill the building blocks with hypotheses. The sticky notes provide great flexibility because they are easy to add, move, or remove. For the purpose of joint 
inquiry in workshop settings (as opposed to analysis and specification), using sticky notes in the building blocks seems appropriate.

DP3.3. Presentation: The visual inquiry tools should be designed in a way that creates tangible marks of the hypotheses and solutions so that they are easy to present, refer to, or criticize. Sticky notes provide a good means to add tangible and visible hypotheses and other elements to the discussion so that they can be presented and criticized by individuals both inside or outside of the team. Presenting and keeping tangible marks regarding a version of a solution on the tool itself allows users to plan the activities necessary to attain future goals and assess progress.

\subsubsection{Artifact Mutability}

Gregor and Jones (2007) underline the importance of capturing the mutability and the inherently dynamic nature of design theories. Design science researchers must account for mutability to inform future designers on the changing conditions of the prescriptive statements they develop (Gregor \& Livari, 2007). Because the presented artifacts are designed iteratively and in a spirit of continuous improvement, they are mutable in nature. The analysis of the differences between the three projects outline several principles of flexibility that can be anticipated in the development of the tool, even though they are not the fundamental characteristics of what constitutes a visual inquiry tool.

The cross-project analysis allowed us to identify three different forms of this mutability: (1) flexibility of use, (2) flexibility of evolution, and (3) flexibility of integration. First, the use of the artifact can deviate from its initial purpose. There may be uses of the tool that deviate from the directions for use in the design theory and to some extent transform the nature of the artifact. For instance, the Business Model Canvas aimed to design a business model and strategize about it, but we have already identified fourteen different uses of the Business Model Canvas. For example, it has been used as a dashboard for setting numerical objectives within each building block (e.g., number of customers to reach with a new value proposition) rather than to ideate the content of the building blocks.

Second, the evolution of the artifact is flexible. Simon (1996) sees this as a possibility for the artifact to be redesigned via feedback loops. Once the designers have developed a rigorous conceptual model, its instantiation can be accomplished in many different ways and using different supports. For instance, the Team Alignment Map was first instantiated as a mobile application, but users expressed interest in having a paper-based shared visual instead. Our design theory can also be instantiated in CAD tools. Third, it is possible to integrate different instantiations of the design theory. Because the tools seek to address a specific management concept, they do not and cannot cover all the aspects of a specific problem. The visual inquiry tools can be combined to form a toolbox of inquiry. This was reflected in the Value Proposition Canvas as a plug-in for the Business Model Canvas. Another illustration can be seen in the teams who use the Team Alignment Map to design their coordination for the implementation of the strategy they defined through the Business Model Canvas.

\section{Discussion}

As we outlined at the start, the goal of our study was to (1) formalize the design knowledge of three visual inquiry tools into prescriptive guidance, and (2) outline how design knowledge can be accumulated within and across multiple projects. Hereafter, we discuss the findings of our analysis and how they support these two goals.

\subsection{The outcome: The Design Theory}

A major concern in DSR has been the means through which design knowledge can be accumulated and formalized to provide effective means for future design science researchers to build on existing cases (e.g., Chandra-Kruse et al., 2016; Gregor \& Jones, 2007; Gregor et al., 2013; Gregory \& Muntermann, 2014; Kuechler \& Vashnavi, 2012; Lee et al., 2011). Our analysis suggests that the formalization of design knowledge in the form of a design theory using Gregor and Jones's (2007) framework provides a valuable and effective medium for communicating and replicating design knowledge. In the Business Design Summit, the design knowledge was shared through the description of the development process and the explanation of the design features of the Business Model Canvas and the Value Proposition Canvas. Thus, the communicated design knowledge focused on the solution domain, as per Meth et al. (2015). In our design theory, we abstracted the development process and design features to develop design principles that bridge the problem and the solution domains. We therefore concur with Chandra et al. (2015) that design principles provide a valuable means to capture and communicate design knowledge. We framed design principles by outlining the design requirement (problem side) and abstract design features that support the design requirement (solution side).

Another point that calls for further discussion is the tension between developing abstract design principles that can be used for multiple instantiations and the need for these principles to be actionable and clear enough to provide valuable prescriptions to designers, as noted by Lukyanenko and Parsons (2013). Various scholars have developed prescriptions and evaluation criteria for the quality of design theories and principles (e.g., Aier \& Fischer, 2011; Chandra et al., 2015). Designers 
should simultaneously assess whether their design principles are projectable (i.e., they can be projected onto multiple instantiations) and clearly framed. In our case, some level of abstraction was required because we drew the design principles from three projects (while most developments in DSR focus on single projects) and aimed for a design theory that could be used for a variety of strategic management problems. The particularity of our design theory is that it can be projected onto a large class of problems. As noted by Baxter et al. (2007), design knowledge may be easily reused for problems that are similar (for which contextspecific and rich design knowledge can be developed), but challenges arise when problems are more generic (for which the design knowledge must be abstract yet actionable enough).

Our experiences underlined the importance of making use of the descriptions and examples of the design principles to facilitate understanding and provide illustrations that designers can rely on. In our view, our design theory cannot be used as a standalone artifact, since illustrations of the design principles may be required when design principles are framed at an abstraction level that can encompass multiple artifacts. In such situations, descriptions and illustrations from different cases can provide future developers with concrete projections of the design principles. This is reflected in the expository instantiations, as discussed by Gregor and Jones (2007). We also join Chandra et al. (2015) in their suggestion that design principles should be material and action-oriented, i.e., they should "prescribe what an artifact should enable users to do and how it should be built in order to do so." (p. 4043). We follow their recommendation by framing design principles in a way that each presents abstracted design features and the design requirements they address.

On another note, our design theory not only provides effective support for designing visual inquiry tools, it also provides a timely contribution to developers and practitioners. Our design theory has attracted interest from developers such as Strategyzer, the company involved in the development and the commercialization of the Business Model Canvas and the Value Proposition Canvas, which has integrated these tools into workshops to help experts in specific management domains design visual inquiry tools. Further, the Business Design Summit, which attracted 280 practitioners and scholars, punctuated the need for prescriptive knowledge regarding how to design visual inquiry tools. Also, since the development of visual inquiry tools is growing continuously (e.g., Campbell et al., 2017; Gruber \& Tal, 2017; Habermann \& Schmidt, 2014; Kalbach, 2016; van der Pijl et al., 2016), we expect our design theory to be useful for some time into the future. Also, two of the co-authors of this paper are developing applications of the design theory to brand identity design and management (Elikan \& Pigneur, 2019).

Our design theory is mutable, which provides insights into the potential expansion of our study, and is also flexible in its evolution since it can be instantiated into different media. Thus, we have laid the foundation of what would be required to develop CAD inquiry tools. The conceptual framework of the visual inquiry tool serves as a basis for the specification of the data architecture of the CAD inquiry tool. The conceptual framework developed through our design theory can be translated into a formal ontological language, such as the web ontology language (OWL) or the lexical OWL ontology matcher (LOOM). The design theory can also be used to inform the design of the CAD inquiry tool's interface. However, our design theory does not specifically address such tools, which calls for further development tailored to CAD.

Our design theory is also flexible in its integration with other visual inquiry tools and tools that address specific components (building blocks) of the visual inquiry tool, and could stimulate the development of this new generation of tools. It is possible to foresee the development of a toolbox for managers, which would be an inventory of the strategic management problems faced by most practitioners; a specific visual inquiry tool could be dedicated to each of these problems. Notably, such a toolbox would not lead to the replacement of any existing management tool; rather, the visual inquiry tools would be used as a first step toward addressing a strategic management problem before employing other tools for decisionmaking, analysis, specification, or implementation purposes.

\subsection{The Process: Design Knowledge Accumulation, Abstraction, and Formalization}

To develop the design theory, we analyzed the design knowledge that we accumulated, adapted, extended, and formalized within and across the three DSR projects. The process of developing the design knowledge in the design theory occurred across five primary stages, as outlined in the methodology (Figure 4). Given the lack of guidance and illustration for theorizing (abstracting) knowledge derived from multiple projects in DSR, our methodological approach offers an example from which other design science researchers can take inspiration. In fact, most studies have either focused on how to conduct (often single-project) DSR (e.g., Hevner et al., 2007; Peffers et al., 2007) or theorize on the basis of single projects (e.g., Lee et al., 2011; Mandviwalla, 2015), what constitutes theoretical design knowledge contributions (e.g., Baskerville, Kaul \& Storey, 2015; Baskerville, Baiyere, Gregor, Hevner \& Rossi, 2018; Gregor \& 
Hevner, 2013; Kuechler \& Vaishnavi, 2012), or how to present the theorized design knowledge (e.g., Chandra et al., 2015; Gregor \& Jones, 2007). The lack of methodological guidance for conducting multiple-project analyses led us to follow some principles that have been developed outside the DSR stream (e.g., Fereday \& MuirCochrane, 2006; Miles \& Huberman, 2010).

Thus, we have proposed a hybrid approach to theorization that incorporates the conventional activities of multiplecase studies to identify the different levels of design knowledge outlined by Meth and colleagues (2015) and the framework by Lee et al. (2011). We performed an iterative (retroductive) analysis between the design requirements and the design features across the three projects until we could formulate design principles and the other components of a design theory. These different design knowledge levels may be used as input for the thematic analysis of qualitative data when analyzing multiple projects. Our methodological approach allowed us to untangle the layers of form and function from the artifacts so that they can be compared and formalized into a more abstract design theory. Our methodological approach can also be replicated for single-project studies to formulate a design theory.

This paper presents a specific instance of knowledge accumulation in DSR, namely that of theorizing and abstracting knowledge derived from multiple projects into a design theory. Our goal was to formalize the instance design knowledge into more general and abstract design knowledge that can be projected onto a broader (less situated) class of problems (i.e., developing visual inquiry tools for strategic management problems). We have illustrated that for such theorization and knowledge accumulation, both the design features and design requirements of the three artifacts had to be abstracted. Thus, the design features comprised the entry points: since the decision to conduct this study was based on the apparent similarity between the three visual inquiry tools, we believed that design knowledge could be accumulated across the projects. The similarity in design features facilitated the comparison of the projects as well as the accumulation of design knowledge, and the formalization of this knowledge into a design theory. That is, the knowledge accumulation through theorization was driven by the solution domain, which corresponds to synthesizing midrange designs, according to Offermann et al. (2011).

We have also illustrated the importance of identifying the practical problems faced by practitioners and the design requirements that must be fulfilled in order to address these problems. This was reflected in the analysis of the development process of the three projects, which included three primary cycles. In each cycle, the researchers were concerned with a different problem, for which they proposed different solutions, often through the development of new artifacts. The evolution of the problems in the three projects was related to the fundamental shortcomings of the existing artifacts. For instance, the Business Model Ontology did not allow practitioners to design business models, thus driving researchers to develop the Business Model Canvas. Therefore, the evolution of the problems did not relate to improvements or situated adaptations of tools; rather, they called for new affordances. Based on our study, we suggest that the analysis of the limitations of a tools' affordances to address certain design requirements may provide entry points for analyzing how design knowledge fundamentally evolves across time, beyond the continuous improvement of solutions. In fact, in the three projects, the evolution of the design requirements called for the instantiation of the conceptual model in different formats, each of which allowed for certain specific actions (e.g., the COOPilot App for testing the level of team coordination and the Team Alignment Map for jointly inquiring into the domains for team coordination). Thus, identifying the evolution of the design requirements may allow researchers to analyze how the design decisions and intuitions for the development of solutions evolve.

We also raise a critical point regarding the presentation of multiple-project analyses in DSR. In fact, we encountered the same concerns that have been identified in other disciplines. For descriptive multiple-case studies, Eisenhardt and Graebner (2007) highlighted the tensions that researchers must manage between providing a rich story about the cases and staying within space constraints. Single-case studies (analogous to single DSR projects) are, in fact, easier to present because the richness of the qualitative data is in line with a rich description of the case (DSR projects). With multiple cases, the challenge is to manage the tradeoff between a story that is rich and having a well-grounded theoretical development. We chose to manage this tension by providing only the main points that readers must understand regarding the projects (motivation for the tool's development, description of the tool, development process, and adoption). A key aspect stressed by Eisenhardt and Graebner is to relate the cases in a way that is interesting to the reader so that they want to read more. We translated our data analysis's results into a storyline that illustrates how design knowledge can accumulate and become more mature and reusable over time (Figure 10). Also, this way of structuring the presentation of analysis chronologically by identifying what each project brought to the subsequent one allowed us to avoid unnecessary repetitions and overly descriptive analyses. We contend that this may seem counterintuitive for the abductive or retroductive nature of DSR (Lee et al., 2011; Mueller \& Urbach, 2013) since presenting results in this way could suggest that the theory was developed through deduction. However, this issue is easy to overcome if the abductive nature of the methodology is clearly explained and outlined. 


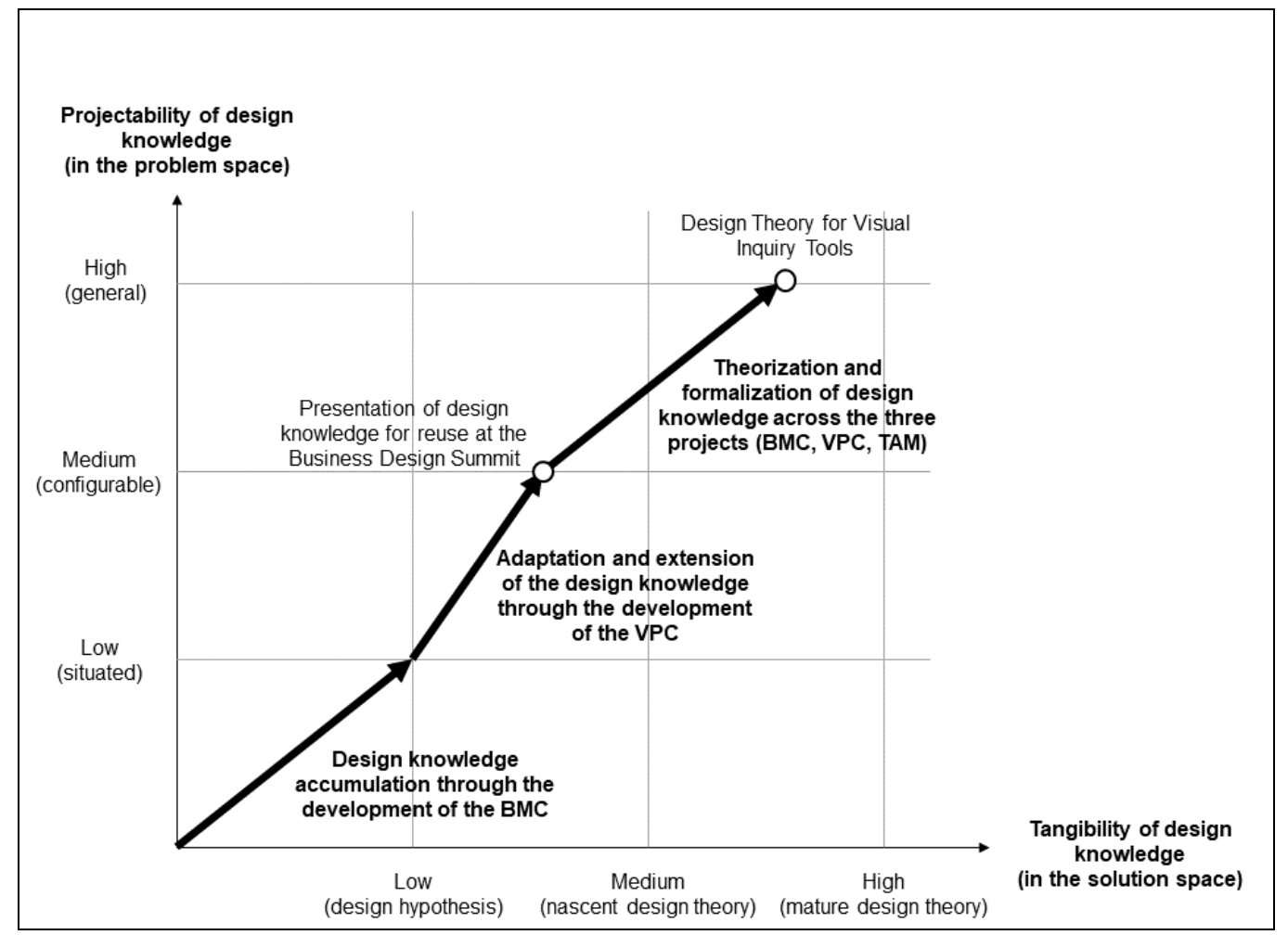

Figure 10. Accumulation of the Design Knowledge across all Cases

\section{Limitations}

The first limitation we must highlight is the lack of a summative evaluation of the design theory. While we based the development of the design theory on three DSR projects that have been extensively evaluated, we do not propose an evaluation of the design theory itself. Therefore, a subsequent study would be required to evaluate the design theory through a lab or field experiment. The experimental task would require management designers to develop visual inquiry tools for a variety of strategic management problems (e.g., strategic alignment, organization vision design, branding management). Such research could explore whether designers who are provided with the design theory develop tools that score higher on the five testable propositions according to users or external design experts. The evaluation of the usability of the design theory itself should also be considered in order to assess the extent to which the design theory is easy to implement and understand. Overall, such an evaluation should consider both the outcome of using the design theory and the process of using the design theory.

Also, we note a limitation regarding the sampling of the DSR projects. We based the current paper on a convenient yet critical sample. The three DSR projects represent critical cases because they have been used extensively and were the only ones, to the best of our knowledge, that explicitly followed a DSR approach and related the design knowledge accumulated in academic outlets. Also, we chose these projects in order to have access to data through our direct involvement in the projects and ruled out other DSR projects for visual inquiry tools. This allowed us to have access to the design rationales and design decisions regarding the three visual inquiry tools throughout the projects' lifecycles. This may limit the usability of our methodological process (Figure 4), since design science researchers seeking to accumulate design knowledge across multiple projects may have difficulties identifying all the design requirements and design features if they are not directly involved in the projects. Thus, we need research to validate, extend, or challenge our methodological process that is based purely on published data.

Finally, and related to the above, we also reflect on our theorization methodology. We followed a hybrid approach, combining both theoretical frameworks and processes in DSR and the qualitative social sciences. Future studies that accumulate knowledge across multiple projects may also build on the qualitative analysis of published DSR papers since the number of studies that formalize design knowledge in conferences and papers is steadily rising (Dolata, Kilic $\&$ Schwabe, 2015). This was not possible in our paper, as a considerable part of the Business Model Canvas project was completed before IS outlets were encouraging and/or accepting DSR studies. 


\section{Conclusion}

In this paper, we illustrate how design knowledge can be accumulated within and across DSR projects to develop design theories that can apply to a broad class of problems. Our research project was motivated by the need to have prescriptive knowledge for developing visual inquiry tools that address strategic management problems. Our analysis allowed us to understand that the accumulation and formalization of design knowledge are valuable for tools that share similar characteristics such as design features. Our methodological process can serve as guidance for researchers who wish to develop design theories based on multiple DSR projects.

Our design theory outlined 12 design principles along three categories (conceptual model, shared visualization, and directions for use) to guide the design of visual inquiry tools and formulated five testable propositions that designers can rely on for the evaluation. Owing to its projectability on multiple strategic management problems, our design theory is not related to specific instance problems. It can be used for management problems that display the properties of strategic management problems (i.e., hard to define, complex to solve, and no single solution) and that require joint inquiry from cross-boundary teams.

On a general note, we illustrated the opportunities that the IS discipline offers for contributing to the management discipline by developing design theories. Van Aken (2004) stressed the need for management research to provide practical and prescription-driven knowledge in addition to descriptive theoretical developments. He argued that management research suffers from a lack of relevance and impact in the business world owing to the paucity of academic and prescriptive knowledge on how to solve a class of managerial problems. Thus, he called for more "fieldtested and grounded technological rules to be used as design exemplars of managerial problem solving." (p. 221). Osterwalder and Pigneur (2013) suggest that the IS discipline is well-equipped to contribute to the design of management tools as it has a long tradition in DSR. We concur that the IS discipline can build on its strength in the modeling, formalization, and representation of practical problems to design solutions for the realities of management. Our study is an illustration of how the IS discipline can contribute to management research - and still remain true to its own identity — by designing visual inquiry tools for a variety of strategic management problems. 


\section{References}

Aier, S., \& Fischer, C. (2011). Criteria of progress for information systems design theories. Information Systems and E-Business Management, 9(1), 133-172.

Aken, J. E. V. (2004). Management research based on the paradigm of the design sciences: The quest for field-tested and grounded technological rules. Journal of Management Studies, 41(2), 219-246.

Aldea, A., Iacob, M. E., van Hillegersberg, J., Quartel, D., \& Franken, H. (2018). Strategy on a Page: An ArchiMate-based tool for visualizing and designing strategy Intelligent Systems in Accounting, Finance and Management, 25(2), 86-102.

Applegate, L. M., \& Collura, M. (2000). Emerging E Business Models: Lessons from the Field. Harvard Business School Press.

Avdiji, H. (2018). Supporting the challenges of crossboundary teamwork through design science research (Doctoral dissertation, University of Lausanne, Lausanne, Switzerland).

Avdiji, H., Missonier, S., \& Mastrogiacomo, S. (2015). Understanding is team coordination in real time: A process approach to coordination. Proceedings of the Thirty-Sixth International Conference on Information Systems.

Avdiji, H., \& Missonier, S. (2018). A design approach to team coordination. Revue Tranel, 68, 97-106.

Baskerville, R., Kaul, M., \& Storey, V. C. (2015). Genres of inquiry in design-science research: Justification and evaluation of knowledge production. MIS Quarterly, 39(3), 541-564.

Baskerville, R., Baiyere, A., Gregor, S., Hevner, A. \& Rossi, M. (2018). Design science research contributions: Finding a balance between artifact and theory. Journal of the Association for Information Systems, 19(5), 358-376.

Baxter, D., Gao, J., Case, K., Harding, J., Young, B., Cochrane, S. \& Dani S. (2007). An engineering design knowledge reuse methodology using process modeling. Research in Engineering Design, 18(1), 37-48.

Ben Mahmoud-Jouini, S., Midler, C., \& Silberzahn, P. (2016). Contributions of design thinking to project management in an innovation context. Project Management Journal, 47(2), 144-156.

Blank, S. (2013). Why the lean start-up changes everything. Harvard Business Review, 91(5), 63-72.
Boland, R. J., \& Collopy, F. (2006). Managing as designing. Stanford University Press.

Boland, R. J., Collopy, F., Lyytinen, K., \& Yoo, Y. (2008). Managing as designing: lessons for organization leaders from the design practice of Frank O. Gehry. Design Issues, 24(1), 10-25.

Braha, D., \& Reich, Y. (2003). Topological structures for modeling engineering design processes. Research in Engineering Design, 14(4), 185199.

Brown, T., and Martin, R. L. (2015). Design for action. Harvard Business Review, 93(9), 57-64.

Buchanan, R. (1992). Wicked problems in design thinking. Design Issues, 8(2), 5-21.

Cabantous, L., \& Gond, J. P. (2011). Rational decision making as performative praxis: Explaining rationality's éternel retour. Organization Science, 22(3), 573-586.

Camillus, J.C. (2008). Strategy as a wicked problem. Harvard Business Review, 86(5), 99-106.

Campbell, A., Gutierrez, M., \& Lancelott, M. (2017). Operating Model Canvas: Aligning operations and organization with strategy (1st ed.). Van Haren Publishing.

Cannon-Bowers, J. A., \& Salas, E. (2001). Reflections on shared cognition. Journal of Organizational Behavior, 2(2), 195-202.

Carlile, P. R. (2004). Transferring, translating, and transforming: An integrative framework for managing knowledge across boundaries. Organization Science, 15(5), 555-568.

Chandra Kruse, L., \& Nickerson, J. V. (2018). Portraying design essence. Proceedings of the 51st Hawaii International Conference on System Sciences.

Chandra, L., Seidel, S., \& Gregor, S. (2015). Prescriptive knowledge in IS research: Conceptualizing design principles in terms of materiality, action, and boundary conditions. In Proceedings of the 48th Hawaii International Conference on System Sciences.

Checkland, P., \& Scholes, J. (1990). Soft systems methodology in practice. Chichester, UK: Wiley.

Clark, H. H. (1996). Using language. Cambridge, UK: Cambridge University Press.

Clegg, S. R., Carter, C., Kornberger, M., \& Schweitzer, J. (2011). Strategy: Theory and practice. SAGE. 
Comi, A., \& Bresciani, S. (2017). Design thinking and techniques in management teams: Understanding the role of visual facilitation. In Proceedings of the Design Management Academy Conference.

Cooper, R., Junginger, S., \& Lockwood, T. (2009). Design thinking and design management: A research and practice perspective. Design Management Review, 20(2), 46-55.

Dalsgaard, P. (2017). Instruments of inquiry: Understanding the nature and role of tools in design. International Journal of Design, 11(1), 21-33.

Détienne, F. (2005). Collaborative design: Managing task interdependencies and multiple perspectives. Interacting with Computers, 18(1), 1-20.

Dolata, M., Kilic, M., \& Schwabe, G. (2015). Unpacking the artifact knowledge: Secondary data analysis in design science research. Proceedings of the International Conference on Design Science Research in Information Systems (pp. 327-324).

Dunne, D., \& Martin, R. (2006). Design thinking and how it will change management education: An interview and discussion. Academy of Management Learning \& Education, 5(4), 512523.

Dym, C. L., Agogino, A. M., Eris, O., Frey, D. D., \& Leifer, L. J. (2005). Engineering design thinking, teaching, and learning. Journal of Engineering Education, 94(1), 103-120.

Edmondson, A. C., \& Harvey, J. F. (2017). Crossboundary teaming for innovation: Integrating research on teams and knowledge in organizations. Human Resource Management Review.

Eisenhardt, K. M. (1989). Building theories from case study research. Academy of Management Review, 14(4), 532-550.

Eisenhardt, K. M., \& Graebner, M. E. (2007). Theory building from cases: Opportunities and challenges. Academy of Management Journal, 50(1), 25-32.

Elikan, D., \& Pigneur, Y. (2019). A Visual Inquiry Tool for Brand Identity. Proceedings of the 52nd Hawaii International Conference on System Sciences.

Espinosa, J. A., Cummings, J. N., Pearce, B. M., \& Wilson, J. M. (2002). Research on teams with multiple boundaries. In Proceedings of the 35th Annual Hawaii International Conference on System Sciences.
Farjoun, M. (2010). Beyond dualism: Stability and change as a duality. Academy of Management Review, 35(2), 202-225.

Feinleib, D. (2011). Why startups fail: And how yours can succeed. Apress,

Fereday, J., \& Muir-Cochrane, E. (2006). Demonstrating rigor using thematic analysis: A hybrid approach of inductive and deductive coding and theme development. International journal of qualitative methods, 5(1), 80-92.

Fritscher, B., \& Pigneur, Y. (2009). Supporting business model modelling: A compromise between creativity and constraints. In International Workshop on Task Models and Diagrams for User Interface Design (pp. 2843). Springer.

Fritscher, B., \& Pigneur, Y. (2014a). Visualizing business model evolution with the business model canvas: Concept and tool. In Proceedings of the 16th Conference on Business Informatics.

Fritscher, B., \& Pigneur, Y. (2014b). Computer aided business model design: analysis of key features adopted by users. Proceedings of the 47th Hawaii International Conference on System Sciences.

Gordijn, J., Osterwalder, A., \& Pigneur, Y. (2005). Comparing two business model ontologies for designing e-business models and value constellations. BLED Proceedings.

Gray, D. W. (2015). Can Culture Be Designed? In D. Simon \& C. Schmidt (Eds.), Business Architecture Management (pp. 125-139). Springer.

Gregor, S. (2009). Building theory in the sciences of the artificial. Proceedings of the 4th international DESRIST conference.

Gregor, S., \& Jones, D. (2007). The anatomy of a design theory. Journal of the Association for Information Systems, 8(5), 312-335.

Gregor, S., \& Iivari, J. (2007). Designing for mutability in information systems artifacts. In D. N. Hart \& S. Gregor (Eds.), Information systems foundations: theory, representation and reality (pp.3-24). Australian National University Press, 2007.

Gregor, S., \& Hevner, A. R. (2013). Positioning and presenting design science research for maximum impact. MIS Quarterly, 37(2), 337355 .

Gregory, R. W, \& Muntermann, J. (2014). Research note-Heuristic theorizing: Proactively 
generating design theories. Information Systems Research, 25(3), 639-653.

Gruber, M., De Leon, N., George, G., \& Thompson, P. (2015). Managing by design. Academy of Management Journal, 58(1), 1-7.

Gruber, M. \& Tal, S. (2017). Where to Play: 3 steps for discovering your most valuable market opportunities. FT Publishing International.

Habermann, F., \& Schmidt, K. (2014). The Project Canvas. A visual tool to jointly understand, design, and initiate projects. https:// gumroad.com/1/GuGZ.

Hamel, G. (2000). Leading the revolution. Harvard Business School Press.

Henderson, B. D. (1979). The product portfolio: growth share matrix of the Boston Consulting Group. In H. Mintzberg \& J. B. Quinn (Eds.), The strategy process: Concepts, contexts, cases (pp. 678-680). Pearson.

Hevner, A.R., March, S.T., Park, J. and Ram, S. (2004). Design science in information systems research. MIS Quarterly, 28(1), 75-105.

Horn, R. E., \& Weber, R. P. (2007). New tools for resolving wicked problems: Mess mapping and resolution mapping processes. Strategy Kinetics LLC.

Jarratt, D., \& Stiles, D. (2010). How are methodologies and tools framing managers' strategizing practice in competitive strategy development? British Journal of Management, 21(1), 28-43.

Jarzabkowski, P., \& Kaplan, S. (2015). Strategy toolsin-use: A framework for understanding "technologies of rationality" in practice. Strategic Management Journal, 36(4), 537558.

John, T., \& Kundisch, D. (2015). Why fit leads to surprise: An extension of cognitive fit theory to creative problems. Proceedings of the 36th International Conference on Information Systems.

Kalbach, J. (2016). Mapping experiences: A complete guide to creating value through journeys, blueprints, and diagrams. O'Reilly Media, Inc.

Kaplan, R. S., Norton, D. P., \& Davenport, T. H. (2004). Strategy maps: Converting intangible assets into tangible outcomes. Harvard Business Press.

Katzenbach, J. R., \& Smith, D. K. (2015). The wisdom of teams: Creating the high-performance organization. Harvard Business Review Press.
Klein, H. K., \&, Myers, M. D. (1999). A set of principles for conducting and evaluating interpretive field studies in information systems. MIS Quarterly, 23(1), 67-94.

Kuechler, W., \& Vaishnavi, V. (2012). A framework for theory development in design science research: multiple perspectives. Journal of the Association for Information Systems, 13(6), 395-423.

Lee, C. F., \& Amjadi, M. (2014). The role of materiality: Knowing through objects in work practice. European Management Journal, 32(5), 723-734.

Lee, A. S., \& Baskerville, R. L. (2003). Generalizing generalizability in information systems research. Information Systems Research, 14(3), 221-243.

Lee, J., Pries-Heje, J., \& Baskerville, R. (2011). Theorizing in design science research. In H. Jain, A. Sinh, \& P. Vitharana (Eds.), ServiceOriented Perspectives in Design Science Research (pp. 1-16). Springer.

Liedtka, J. (2018, July). Innovation, strategy, and design: Design thinking as a dynamic capability. Academy of Management Proceedings.

Lukyanenko, R., \& Parsons, J. (2013). Reconciling theories with design choices in design science research. DESRIST Conference Proceedings.

Malone, T. W., \& Crowston, K. (1994). The interdisciplinary study of coordination. ACM Computing Surveys, 26(1), 87-119.

Mandviwalla, M. (2015). Generating and justifying design theory. Journal of the Association for Information Systems 16(5), 314-344.

Martin, R. L. (2009). The design of business: Why design thinking is the next competitive advantage. Harvard Business Press.

Mastrogiacomo, S., Missonier, S., \& Bonazzi, R. (2014). Talk before it's too late: Reconsidering the role of conversation in information systems project management. Journal of Management Information Systems, 31(1), 47-78.

McGee, J., \& Thomas, H. (1986). Strategic groups: theory, research and taxonomy. Strategic Management Journal, 7(2), 141-160.

Meth, H., Mueller, B., \& Maedche, A. (2015). Designing a requirement mining system. Journal of the Association for Information Systems, 16(9), 799-837. 
Miles, M. B., \& Huberman, A. M. (2010). Qualitative data analysis: An expanded sourcebook. SAGE.

Mintzberg, H. (1979). The structuring of organization: A synthesis of the research. Prentice-Hall.

Missonier, S., Avdiji, H., \& Mastrogiacomo, S. (2014). Applying psycholinguistic concepts to IS project management tool design. Proceedings of the 22nd European Conference on Information Systems.

Mueller, B., \& Urbach, N. (2013). The why, what and how of theories in IS research. Proceedings of the 34th International Conference on Information Systems.

Nicolini, D., Mengis, J. \& Swan, J. (2012). Understanding the role of objects in crossdisciplinary collaboration. Organization Science, 23, 612-629.

Offermann, P., Blom, S., \& Bub, U. (2011). Strategies for creating, generalising and transferring design science knowledge: A methodological discussion and case analysis. Proceedings of the 10th International Conference on Wirtschaftsinformatik.

Okhuysen, G., \& Bechky, B. (2009). Coordination in organizations: An integrative perspective. Academy of Management Annals, 3(1), 463502.

Osterwalder, A. (2004). The Business Model Ontology: A proposition in a design science approach (Doctoral dissertation, University of Lausanne, Lausanne, Switzerland).

Osterwalder, A., \& Pigneur, Y. (2002). An eBusiness model ontology for modeling eBusiness. BLED Proceedings.

Osterwalder, A., \& Pigneur, Y. (2010). Business model generation: A handbook for visionaries, game changers, and challengers. Wiley.

Osterwalder, A., \& Pigneur, Y. (2013). Designing business models and similar strategic objects: The contribution of IS. Journal of the Association for Information Systems, 14, 237 244.

Osterwalder, A., Pigneur, Y., \& Tucci, C. L. (2005). Clarifying business models: Origins, present, and future of the concept. Communications of the Association for Information Systems, 16(1), $1-43$.

Osterwalder, A., Pigneur, Y., Bernarda, G., \& Smith, A. (2014). Value proposition design: How to create products and services customers want. Wiley.
Patton, M. Q. (2002). Two decades of developments in qualitative inquiry: A personal, experiential perspective. Qualitative Social Work, 1(3), 261283.

Peffers, K., Tuunanen, T., Rothenberger, M. A., \& Chatterjee, S. (2007). A design science research methodology for information systems research.Journal of Management Information Systems, 24(3), 45-77.

Piirainen, K. A., \& Briggs, R. O. (2011). Design theory in practice: Making design science research more transparent. In H. Jain, A. Sinha, \& P. Vitharana (Eds.), Service-oriented perspectives in design science research (pp. 47-61). Springer.

Porter, M. E., (1979). How competitive forces shape strategy. Harvard Business Review, 57(2), 137145 .

Ragin, C. 1994. Constructing social research (1st ed.). SAGE.

Razzouk, R., \& Shute, V. (2012). What is design thinking and why is it important? Review of Educational Research, 82(3), 330-348.

Sibbet, D. (2011). Visual teams: Graphic tools for commitment, innovation, and high performance. Wiley.

Siggelkow, N. (2007). Persuasion with case studies. Academy of Management Journal, 50(1), 2024.

Simon, H. (1978). Rationality as process and as product of thought. American Economic Review, 68, 1-16.

Sosa, M. E., Eppinger, S. D., \& Rowles, C. M. (2004). The misalignment of product architecture and organizational structure in complex product development. Management science, 50(12), 1674-1689.

Steen, M., Manschot, M. A. J., \& De Koning, N. (2011). Benefits of Co-Design in Service Design Projects. International Journal of Design, 5(2), 53-60.

Steen, M. (2013). Co-design as a process of joint inquiry and imagination. Design Issues, 29(2), 16-28.

Strategyzer. 2015. The Business Model Canvas: Why and how organizations around the world adopt it. http://blog.strategyzer.com/posts/2015/2/9/ why-and-how-organizations-around-theworld-apply-the-business-model-canvas.

Teece, D. J. (2010). Business models, business strategy and innovation. Long Range Planning, 43(2), 172-194. 
Teece, D., Peteraf, M., \& Leih, S. (2016). Dynamic capabilities and organizational agility: Risk, uncertainty, and strategy in the innovation economy. California Management Review, 58(4), 13-35.

Tzonis, A. (2006). Globalized world, identity, and critical regional architecture. Proceedings of the Modernization and Regionalism: Reinventing Urban Identity Conference.

Ulwick, A. (2005). What customers want. McGrawHill.
Van Aken, J. E. (2004). Management research based on the paradigm of the design sciences: The quest for field-tested and grounded technological rules. Journal of Management Studies, 41(2), 219-246.

Van Der Pijl, P., Solomon, L. K., \& Lokitz, J. (2016). The Design Journey IDEATE. In P. Van der Pijl, J. Lokitz, \& L. K. Solomon (Eds.), How to design a better business: New tools, skills, and mindset for strategy and innovation (1st ed., pp.125-152). Wiley.

Yin, R. K. (1994). Case study research: Design and methods (2nd ed.). SAGE. 


\section{Appendix}

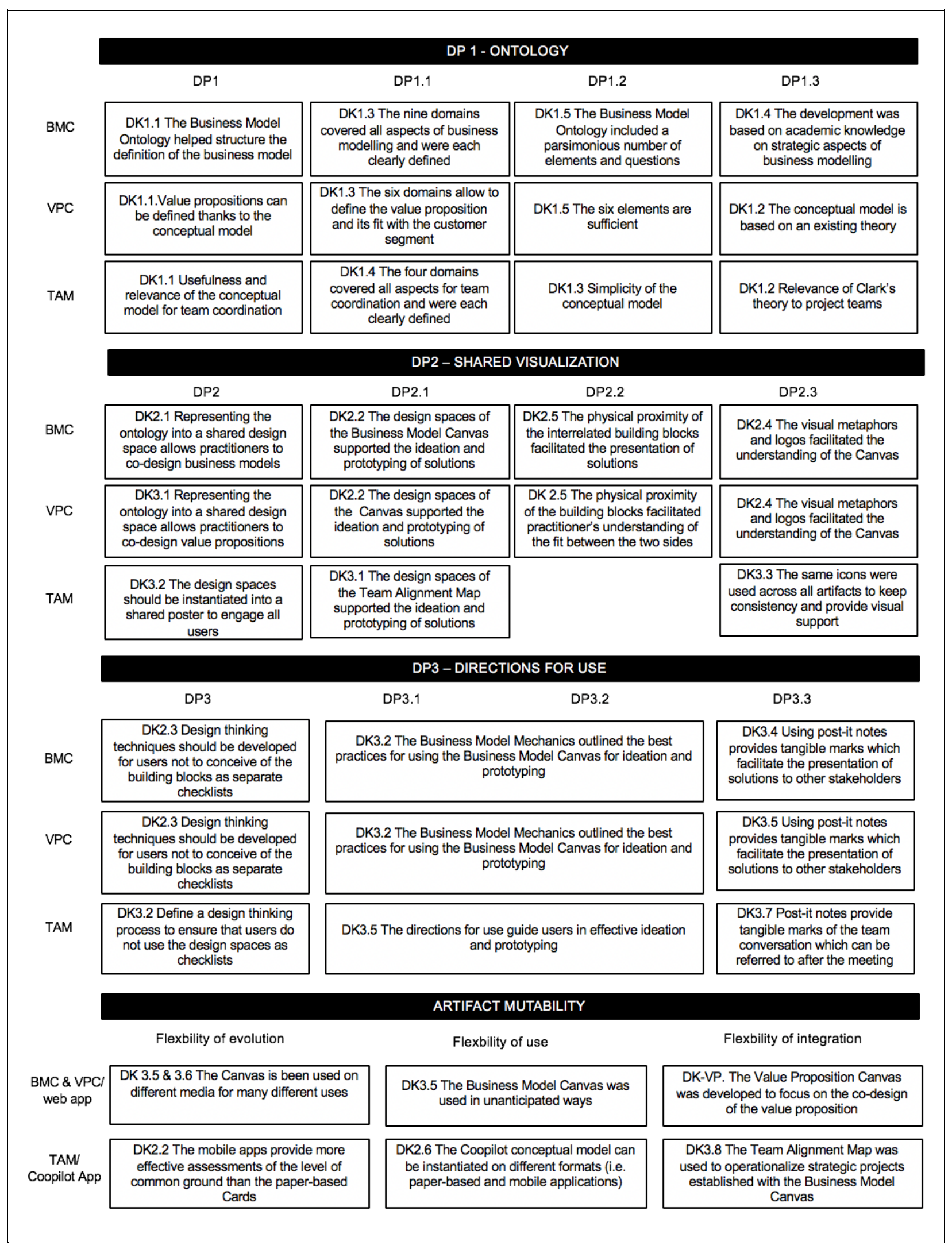

Figure A1. Cross-Project Analysis Matrix of the Accumulated Design Knowledge 


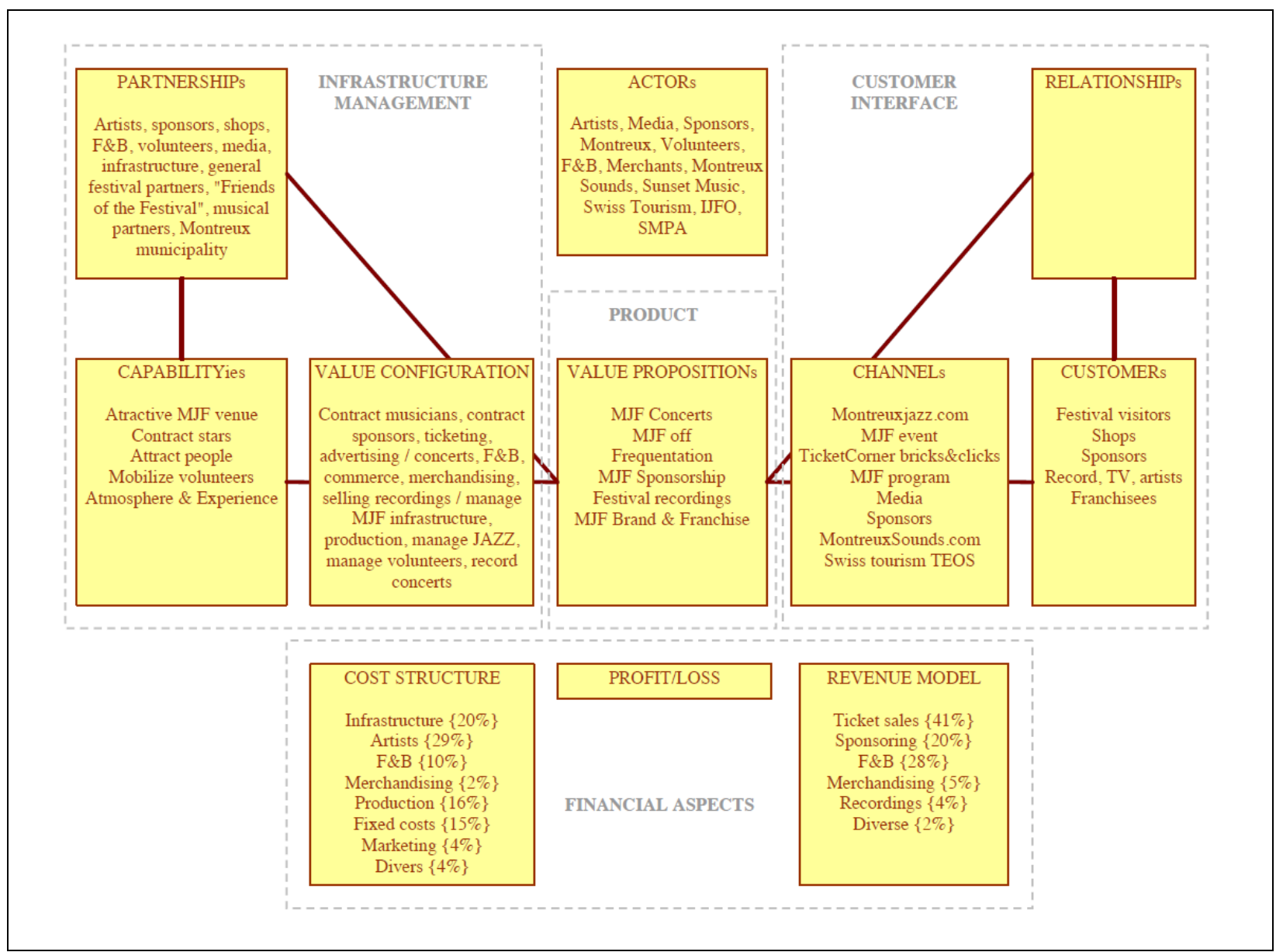

Figure A2. The Business Model Ontology of the Montreux Jazz Festival 


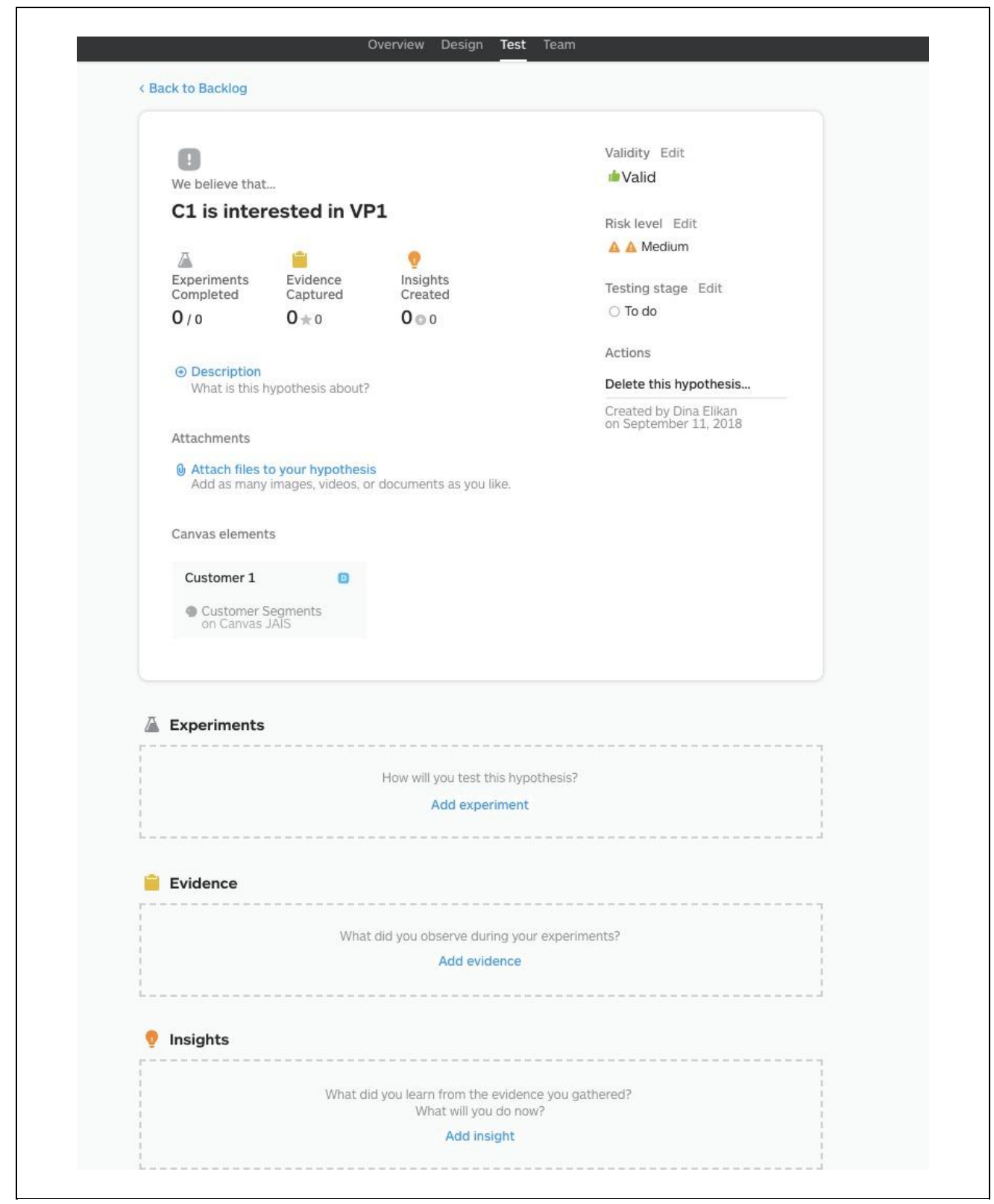

Figure A3. Hypothesis Testing in the SaaS Application 


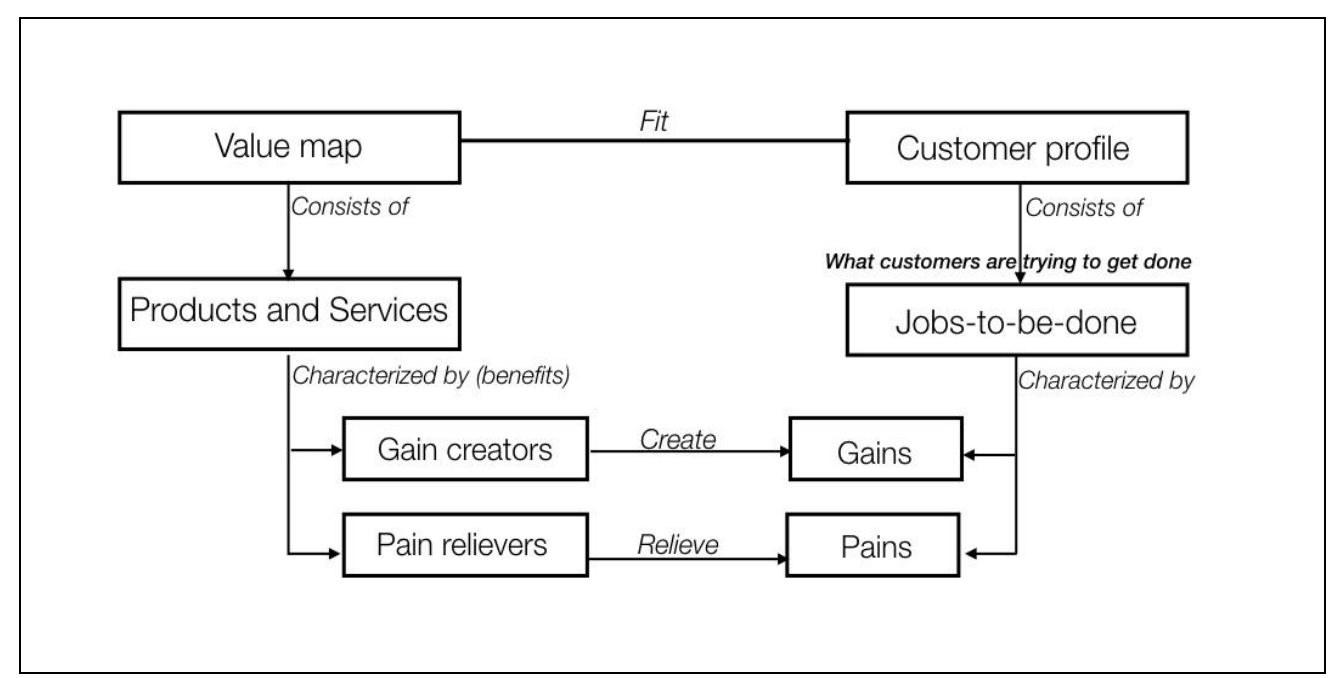

Figure A4. The Value Proposition Conceptual Framework

\begin{tabular}{|c|c|c|c|}
\hline $\begin{array}{c}\text { JOINT } \\
\text { OBJECTIVES }\end{array}$ & $\begin{array}{c}\text { JOINT } \\
\text { COMMITMENTS }\end{array}$ & $\begin{array}{c}\text { JOINT } \\
\text { RESOURCES }\end{array}$ & $\begin{array}{l}\text { JOINT } \\
\text { RISKS }\end{array}$ \\
\hline $\begin{array}{l}\text { I think we all } \\
\text { understand what } \\
\text { we intend to do } \\
\text { together. }\end{array}$ & $\begin{array}{l}\text { I think we are } \\
\text { clear about the } \\
\text { commitments we } \\
\text { have made } \\
\text { towards each } \\
\text { other. }\end{array}$ & $\begin{array}{l}\text { I think everyone } \\
\text { has sufficient } \\
\text { resources to do } \\
\text { his or her part. }\end{array}$ & $\begin{array}{l}\text { I think we are } \\
\text { aware of the risks } \\
\text { we face } \\
\text { collectively. }\end{array}$ \\
\hline $\begin{array}{l}\text { Yes: ok } \\
\text { No: action? }\end{array}$ & $\begin{array}{l}\text { Yes: ok } \\
\text { No: action? }\end{array}$ & $\begin{array}{l}\text { Yes: ok } \\
\text { No: action? }\end{array}$ & $\begin{array}{l}\square \text { Yes: ok } \\
\text { No: action? }\end{array}$ \\
\hline
\end{tabular}

Figure A5. The COOPilot Cards 


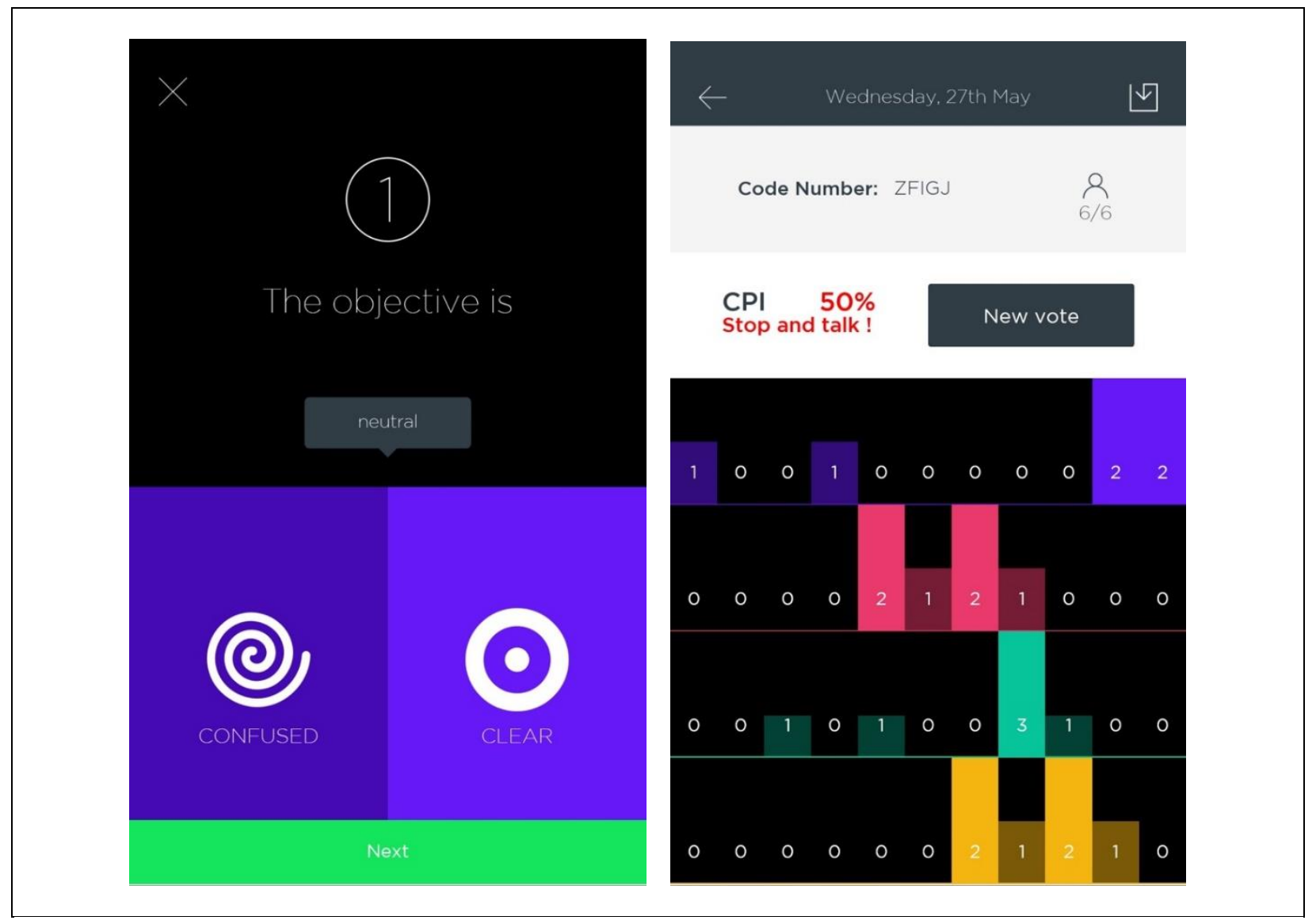

Figure A6. The COOPilot App 


\section{About the Authors}

Hazbi Avdiji completed their doctorate in information systems at HEC Lausanne under the supervision of Prof. Stéphanie Missonier. Following their graduation, they undertook a one-year postdoctoral research program at the University of St. Gallen working on design science research and visual inquiry tools.

Dina Elikan completed her PhD in information systems under the supervision of Prof. Pigneur at HEC Lausanne. Her research interests lay at the intersection between information systems, design, and management. She now works in an innovation lab.

Stéphanie Missonier is a professor of digital strategy and project management at the University of Lausanne and is the director of the Information Systems Department (DESI) at HEC Lausanne. She was also a visiting research scholar at Stanford University. Her research interests focus on designing visual tools for addressing wicked management problems and innovation and she is also interested in subjects devoted to digital innovation such as IS ambidexterity and intrapreneurship and team and cross-boundary collaboration in digital and IS projects. She has published her research in journals such as Journal of Management Information Systems, Organizations Studies, and the International Journal of Project Management.

Yves Pigneur is a professor at University of Lausanne and has held visiting professorships at Georgia State University, University of British Columbia, National University of Singapore, and HEC Montreal. He was the former editor-in-chief of the academic journal Systèmes d'Information \& Management. In 2016, he won the Outreach Award from the Association for Information Systems. Together with Alexander Osterwalder, they invented the Business Model Canvas and co-authored the international bestsellers Business Model Generation and Value Proposition Design. They won the 2015 Strategy Award from Thinkers50 and currently rank \#4 in the Thinkers50 global ranking of the top 50 management thinkers.

Copyright (C) 2020 by the Association for Information Systems. Permission to make digital or hard copies of all or part of this work for personal or classroom use is granted without fee provided that copies are not made or distributed for profit or commercial advantage and that copies bear this notice and full citation on the first page. Copyright for components of this work owned by others than the Association for Information Systems must be honored. Abstracting with credit is permitted. To copy otherwise, to republish, to post on servers, or to redistribute to lists requires prior specific permission and/or fee. Request permission to publish from: AIS Administrative Office, P.O. Box 2712 Atlanta, GA, 30301-2712 Attn: Reprints, or via email from publications@aisnet.org. 